\title{
Relações econômicas internacionais na América Latina: um estudo sobre as percepções das elites parlamentares
}

\author{
Manoel Leonardo Santos ${ }^{1}$ (iD) \\ Fernanda Cimini² \\ Asbel Bohigues $^{3}$
}

Este artigo analisa as percepções dos parlamentares de 17 países da América Latina sobre relações econômicas e internacionais. A questão central é identificar os determinantes da formação das estruturas de preferências dos parlamentares. O artigo procura identificar quais são os determinantes que influenciam as opções expressas pelo parlamentar, colocando em contraste suas opções por relações políticas e econômicas entre países da região versus suas opções por países de outras regiões e as grandes potências econômicas. A análise está dividida em duas partes. A primeira é comparativa, utilizando estatística descritiva e análise de redes. Com essa análise são comparadas as legislaturas/países no nível agregado. A segunda parte desce ao nível do comportamento individual do parlamentar, buscando estimar, com a aplicação de modelos de regressão linear (OLS), o peso de diferentes preditores para a conformação das suas estruturas de preferências. O artigo conclui que as preferências dos parlamentares são fortemente determinadas por variáveis de contexto (estruturais) e por um alto grau de pragmatismo econômico, mas as ideias políticas continuam tendo alguma relevância. Embora em menor monta, a ideologia e as preferências por economias reguladas pelo Estado também ajudam a entender por que alguns parlamentares defendem mais regionalismo político e econômico que outros.

Palavras-chave: elites parlamentares; Poder Legislativo; América Latina; relações econômicas internacionais

\section{Introdução 4}

O que pensam os parlamentares da América Latina sobre as relações internacionais, econômicas e políticas, de seus países e da região? Este artigo analisa as opiniões dos parlamentares sobre o tema em 17 legislaturas/países latino-americanos. Três questões

\footnotetext{
${ }^{1}$ Universidade Federal de Minas Gerais. Departamento de Ciência Política. Belo Horizonte (MG), Brasil. E-mail: <mlwds@hotmail.com>.

2 Universidade Federal de Minas Gerais. Faculdade de Ciências Econômicas. Centro de Desenvolvimento e Planejamento Regional (Cedeplar). Belo Horizonte (MG), Brasil. E-mail: <fcimini@cedeplar.ufmg.br>.

3 Universidade Federal de Minas Gerais. Departamento de Ciência Política. Belo Horizonte (MG), Brasil.

E-mail: <asbogar@rpd.ufmg.br>.

4 Os autores agradecem aos pesquisadores do Nepi (Núcleo de Estudos de Política Comparada e Relações Internacionais da UFPE), especialmente ao professor Marcelo de Almeida Medeiros, os comentários feitos na ocasião da apresentação da primeira versão, em dezembro de 2018, no Recife. Agradecemos também ao professor Alexandre Queiroz Guimarães (Fundação João Pinheiro) os comentários feitos na ocasião do $42^{\circ}$ Encontro Anual da Anpocs, no GT de Relações Internacionais da América Latina. Por fim, agradecemos aos pareceristas de Opinião Pública. Somados, esses comentários agregaram muito ao manuscrito inicial.
} 
relacionadas são objeto de análise. Quais as preferências dos parlamentares em termos de relações bilaterais e multilaterais? Como se distribuem suas preferências em termos das relações entre países da região e com países de outras regiões? Como interagem fatores político-ideológicos e pragmáticos na formação dessas preferências? Para responder a essas questões, utilizam-se duas estratégias analíticas: uma análise descritiva comparativa (estatística descritiva e análise de redes) e uma análise estatística mais robusta, com modelos de regressão, para estimar a força de possíveis determinantes das preferências dos parlamentares.

Há pelo menos dois aspectos relevantes para o debate sobre a participação dos parlamentos e dos parlamentares no que diz respeito às relações internacionais, tanto políticas quanto econômicas, em países da América Latina. O primeiro diz respeito à importância dos jogos em dois níveis, doméstico e internacional, e dos legislativos em questões de caráter distributivo - comércio internacional. O segundo refere-se à influência das elites econômicas nos legislativos, observando os reflexos das demandas empresariais dos grandes setores (industrial, agronegócios e financeiro) no parlamento. Conhecer as preferências dos parlamentares de diferentes países é relevante em relação a ambos os aspectos.

Sendo assim, ainda que, para alguns, possa parecer pouco relevante discutir opiniões dos parlamentares sobre política externa, dado o pouco protagonismo das casas legislativas da região nesses assuntos, os parlamentares formam uma elite política importante em qualquer país. O que, per se, já justifica o esforço. É sabido que o desenho institucional de cada país determina a força dos parlamentos no processo decisório, seja nas grandes decisões, seja na formulação e implementação de políticas públicas. Mas algo existe em comum entre eles. Os parlamentos são os loci das elites políticas de qualquer país, e é neles que são discutidas as mais importantes questões políticas e econômicas.

Com a política externa não é diferente. Em todos os ordenamentos jurídicoconstitucionais, o parlamento tem algum papel na política externa, embora com graus variados de capacidade decisória, mas nenhum país pode formular, implementar ou modificar suas estratégias de política externa ignorando completamente as casas legislativas ${ }^{5}$. Dada essa relevância, a questão central deste artigo é quais os determinantes da formação da estrutura de preferências dos parlamentares em termos de relações internacionais econômicas e políticas?

\footnotetext{
${ }^{5}$ Lopes, Faria e Santos (2016, p. 13) chamam a atenção para uma série de questões que consideram heurísticas para os estudos sobre o ciclo de políticas públicas, no qual se insere a política externa. Pelo menos três questões assinaladas estimulam os estudos do parlamento como ator relevante no processo decisório: (i) What are the institutional channels for communication and influence to link up society and government?; (ii) How does the Constitution regulate the legislative process on international affairs (on issues such as declaration of war, celebration of peace, ratification of international treaties etc.)?; (iii) Are there horizontal and vertical accountability mechanisms applicable to foreign policy? (grifos nossos).
} 
O artigo explora as opiniões dos parlamentares sobre o tema em 17 países da América Latina. Para esta análise foi utilizada a base de dados do projeto "Elites latinoamericanas", da Universidade de Salamanca (Alcántara, 1994-2018).

O artigo está dividido em sete seções, incluindo esta "Introdução". Em "Os parlamentos e a integração econômica na América Latina", é apresentado o problema de pesquisa que motiva o artigo. A velocidade com que esquemas regionalistas foram criados e desmantelados nas últimas décadas suscita dúvidas sobre as preferências e o engajamento das elites políticas em relação à integração regional latino-americana. Motivações políticoideológicas e pragmáticas interagem na conformação de uma pluralidade de projetos de regionalismo político e econômico. Nesse sentido, a seção apresenta o estado da arte desse debate e a proposta de contribuição do artigo. Em "Amostra, dados e estratégias analíticas", discutem-se aspectos metodológicos relacionados à amostra e aos dados e justifica-se a estratégia analítica adotada. Em "Análise descritiva comparativa", são apresentados os resultados da análise descritiva comparativa das preferências dos parlamentares em nível agregado, ou seja, comparando legislaturas/países. Em "Explorando preditores das preferências dos parlamentares", o artigo alterna o nível de análise da perspectiva comparativa para o nível individual do parlamentar. Nessa seção, procura-se estimar, usando modelos de regressão linear, a força de alguns preditores sobre as preferências dos parlamentares, controlando por variáveis estruturais. Por fim temos "Resultados" e "Conclusões".

\section{Os parlamentos e a integração econômica na América Latina}

O fracasso das negociações para a integração econômica com os Estados Unidos, no âmbito do Acordo de Livre-Comércio das Américas (Alca), deu início a uma nova fase nos processos de regionalismo latino-americano. Embora grande parte dos estudos sobre integração regional latino-americana concorde que essa nova fase se distancia de algumas das premissas que marcaram o regionalismo aberto ${ }^{6}$ dos anos 1990 , não há um consenso na literatura sobre os objetivos e resultados alcançados pelos projetos regionalistas que conformaram essa etapa. Consequentemente, observa-se uma proliferação de nomenclaturas para denominá-la, cada uma buscando enfatizar os aspectos que seriam mais "característicos" desse momento: regionalismo pós-liberal (Veiga e Ríos, 2007; Sanahuja, 2009; Briceño-Ruiz e Morales, 2017); regionalismo ideológico (Vigevani et al., 2008; Briceño-Ruiz e Saraiva, 2009); regionalismo de governança regional (Nolte, 2011); regionalismo político-social (Gratius, 2012); quarta onda de regionalismo (Dabène, 2012);

\footnotetext{
${ }^{6}$ O termo "regionalismo aberto" foi cunhado pela Cepal em 1994 para se referir a "(...) un proceso de creciente interdependencia a nivel regional, promovida por acuerdos preferenciales de integración y por otras políticas, en un contexto de liberalización y desregulación capaz de fortalecer la competitividad de la región y, en la medida de lo posible, proporcionar las bases para una economía internacional más abierta y transparente" (Cepal, 1994, p. 8).
} 
regionalismo pós-hegemônico (Riggiorozzi e Tussie, 2012); sub-regionalismo segmentado (Malamud e Gardini, 2012); regionalismo modular (Gardini, 2015), entre outros.

As principais inovações institucionais que marcaram essa fase foram: (i) 0 alargamento do Mercosul, com a entrada de Venezuela e Bolívia, e a ampliação do seu escopo em novas frentes com a criação do Fundo para Convergência Estrutural do Mercosul (Focem), em 2004, e do Parlamento do Mercosul (Parlasul), em 2007; (ii) a criação da Aliança Bolivariana para os Povos de Nossa América (Alba), em 2004, pelos então presidentes da Venezuela, Hugo Chávez, e de Cuba, Fidel Castro, com forte viés anti-hegemônico; (iii) a constituição da União Sul-Americana de Nações (Unasul), em 2008, que visava à colaboração política dos Estados da América do Sul em um rol de mais de 15 áreas temáticas, sendo os principais a cooperação para integração física, por meio do Conselho Sul-Americano de Infraestrutura e Planejamento (Cosiplan), a cooperação na área social, por meio do Conselho de Desenvolvimento Social (CDES), e a cooperação na área de defesa, com a criação do Conselho de Defesa Sul-Americano (CDS); (iv) o projeto do Banco do Sul, lançado em 2007 e institucionalizado em 2011, por iniciativa do então presidente Hugo Chávez, como alternativa contra-hegemônica ao Banco Mundial, ao FMI e ao Banco Interamericano de Desenvolvimento (BID); (v) a criação da Comunidade de Estados Latino-Americanos e Caribenhos (Celac), em 2010, em contraposição à Organização dos Estados Americanos (OEA); e (vi) finalmente, mas na contramão dos demais arranjos regionalistas, a Aliança do Pacífico, criada em 2012, para a construção de uma aliança de livre-comércio, com forte orientação para fora da região, especificamente para o eixo Ásia-Pacífico e Estados Unidos.

Se, por um lado, a proliferação de projetos regionalistas contribuiu para reforçar a visão de fortalecimento do regionalismo latino-americano em uma perspectiva "pós-liberal", por outro, a sobreposição de iniciativas provocou desconfianças quanto à possibilidade de fragmentação e ruptura da cooperação e integração regional (Vivares e Dolcetti-Marcolini, 2015). Estudos que apontam em direção ao primeiro cenário são críticos à visão dominante na literatura de integração regional, que coloca a União Europeia como o modelo universal de regionalismo e ignora modelos alternativos de integração. Segundo essa perspectiva crítica, não se trata de fragmentação, mas da coexistência de diferentes projetos de desenvolvimento que refletem diferentes forças sociais e econômicas intrinsecamente em conflito (Riggiorozzi, 2012).

Já os estudos que apontam em direção ao segundo cenário argumentam que: (i) a ausência de uma liderança centralizadora, capaz de assumir os custos da promoção do comércio e do investimento intrarregião; (ii) a falta de complementaridade econômica entre os países da região, principalmente, das relações comerciais intraindústria; (iii) as oportunidades oferecidas por parceiros econômicos extrarregião, como a China, os Estados Unidos e a União Europeia; (iv) a proliferação de acordos preferenciais de comércio; e (v) a sobreposição de agenda de grupos "setoriais" no comércio internacional, como o G-20, enfraqueceram os esforços políticos de integração regional e a capacidade de esses esquemas regionalistas gerarem ganhos econômicos. 
A pluralidade de projetos e a diversidade de estratégias adotadas pelos países da região têm fomentado o debate sobre os determinantes econômicos e políticos do comportamento dos Estados nos processos de integração regional. Pelo menos três eixos de integração, que expressam diferentes modelos adotados pelos países da região, têm sido exaustivamente trabalhados pela literatura: o eixo de integração aberta, o eixo revisionista e o eixo antissistêmico (Briceño-Ruiz, 2013; Quiliconi e Salgado, 2017; Briceño-Ruiz e Morales, 2017; Atkins, 2018; Bohigues e Rivas, 2019).

O primeiro eixo refere-se à estratégia adotada por Colômbia, Chile, México, Peru, República Dominicana e países da América Central, à exceção da Nicarágua, e suas principais características estão na orientação ideológica neoliberal e na preferência pela integração econômica por meio de acordos de livre-comércio, tais como Nafta e Aliança do Pacífico. Justamente por defender a liberalização comercial, esse modelo não diferencia parceiros regionais de parceiros de fora da região e não prioriza a construção de cooperação política entre os Estados.

O segundo eixo, chamado revisionista, refere-se às estratégias adotadas por Argentina, Brasil, Paraguai e Uruguai. Esse eixo caracteriza-se pelo esforço de aprofundamento e ampliação do escopo da integração regional para além das trocas comerciais, principalmente nas áreas de infraestrutura, comércio, políticas sociais e defesa. O Mercosul, a Unasul e, em alguma medida, a Celac seriam os principais arranjos regionalistas representativos desse eixo.

Já o terceiro caracteriza-se por sua orientação claramente anti-hegemônica e a busca pelo distanciamento em relação aos Estados Unidos. Cuba, Bolívia, Equador, Nicarágua e Venezuela conformariam esse eixo. Esquemas regionalistas como o Banco do Sul e a Alba foram desenvolvidos visando à maior autonomia da região em relação aos países do norte e como movimento de resistência à histórica trajetória de exploração e subordinação aos interesses do centro capitalista.

Por mais de uma década, essa configuração manteve-se estável, mas a cartografia latino-americana começou a se transformar com a crise política vivenciada pela Venezuela a partir da morte do presidente Hugo Chávez (2013), com a mudança na política externa norteamericana no governo Trump (2017) e a vitória dos candidatos de direita na Argentina (2015) e no Brasil (2019). Nesse novo contexto, o eixo revisionista tem se mostrado cada vez mais aberto à integração econômica para fora da região, e a assinatura do acordo entre o Mercosul e a União Europeia fortalece essa direção. Já o eixo antissistêmico perdeu fôlego com os desgastes políticos do governo de Nicolás Maduro e a criação de um novo arranjo institucional, o Prosur (Fórum para o Progresso da América do Sul), protagonizado por Argentina, Brasil e Chile para substituir a Unasul. O eixo de integração aberta, por sua vez, embora tenha ganhado o respaldo ideológico de novos países, como Brasil e Argentina, enfrenta os desafios colocados pelo comportamento protecionista do governo Trump e pela guerra comercial travada com a China. Ainda é cedo para saber se essas mudanças irão 
acentuar a fragmentação do regionalismo latino-americano ou se estaria em curso uma nova fase de convergência sob orientação neoliberal.

As mudanças em curso demonstram a elevada volatilidade das preferências dos países latino-americanos em relação à integração regional e à complexidade dos interesses econômicos e políticos em jogo. A velocidade com que arranjos institucionais foram criados e, posteriormente, desmantelados impõe limites para as abordagens de economia política internacional (EPI) que tratam interesses econômicos e políticos indistintamente. Para Tussie (2015, p. 48), a EPI parte de um pressuposto básico: "a economia é um cenário de lutas de poder", o que significa dizer que economia e política não devem ser separadas na hora de analisar fenômenos nacionais e internacionais. Ao contrário, a ação política está no coração do sistema econômico da mesma forma que os interesses econômicos estão no coração da política, e a autonomia entre ambas as esferas é sempre relativa.

O problema da premissa de congruência entre economia e poder está na pluralidade de combinações possíveis entre as motivações político-ideológicas e as motivações econômicas dos diversos atores que compõem o processo de formulação da política externa. $\mathrm{Na}$ raiz da fragilidade e da pluralidade dos esquemas regionalistas que emergiram no período recente, está a tensão entre orientações ideológicas e pragmatismo econômico. Gardini e Lambert (2011) propõem um modelo de análise do regionalismo latino-americano a partir dessa dicotomia. Segundo os autores, políticas pragmáticas estariam orientadas pelos princípios de utilidade, viabilidade e praticidade, com forte ênfase nas consequências práticas e nos ganhos de médio prazo. Já as políticas ideológicas priorizariam a defesa de uma determinada visão de mundo, quase sempre associada a interesses de curto prazo, vinculados a um grupo político e não necessariamente convergentes com o interesse nacional.

Embora a definição desses conceitos seja objeto de permanente controvérsia, o modelo proposto pelos autores sugere que ideologia e pragmatismo não devem ser tratados como princípios mutuamente exclusivos em política externa. A experiência recente do regionalismo latino-americano reforçaria esse argumento ao indicar que o comportamento adotado pelos países da região em relação aos arranjos regionalistas é caracterizado por diferentes combinações entre ideologia e pragmatismo. Fatores como contexto histórico e político, capacidades estruturais e econômicas relacionadas a recursos naturais, população e tamanho do território, características pessoais dos líderes políticos e o próprio processo decisório de formulação e implementação de política externa influenciariam na interação entre ambos e, consequentemente, na variedade de respostas adotadas pelos países nos processos de integração regional (Gardini e Lambert, 2011).

Nesse modelo, a abertura da "caixa preta" do Estado torna-se imprescindível para a compreensão das estratégias de integração (Lima, 2000; Saraiva, 2008; Vigevani et al., 2008; Medeiros, Teixeira Júnior e Reis, 2017; Caichiolo, 2017). Considerando que a política externa é uma política pública (Salomon e Pinheiro, 2013) e, como tal, é resultado da interação política entre diferentes atores - Executivo, Legislativo, chancelaria, sociedade civil 
e empresariado -, é importante conhecer como as elites políticas e econômicas articulam suas preferências e qual a força do aspecto ideológico e pragmático nesse processo.

Em consonância com uma agenda crescente de estudos voltados para o papel do Legislativo na política externa, este artigo dedica-se à análise das preferências desse subgrupo da elite política. Bohigues e Rivas (2019) analisaram as preferências dos legisladores latino-americanos em relação aos acordos regionais, especificamente acordos de livre-comércio com Estados Unidos, União Europeia, Alba e Aliança do Pacífico. Os autores concluíram que a política externa latino-americana está longe do consenso: as posições ideológicas dos deputados e até mesmo a confiança nos governos russo e chinês condicionam em grande parte o apoio a acordos comerciais ou alianças.

Este artigo busca avançar o trabalho desenvolvido por Bohigues e Rivas (2019) para a compreensão das preferências dos parlamentares latino-americanos em dois aspectos: (i) diferenciando as preferências por relações bilaterais em termos econômicos e políticos; (ii) diferenciando as preferências por relações bilaterais intrarregionais e extrarregionais. A questão central é entender quais os determinantes da formação da estrutura de preferências dos parlamentares na agenda de relações internacionais. Especificamente, quais variáveis influenciam a escolha entre colaboração intrarregional e colaboração extrarregional?

De forma resumida, espera-se que o modelo possa testar conjuntamente a hipótese das motivações político-ideológicas versus a hipótese do pragmatismo econômico. A primeira assume que o que determina as escolhas dos parlamentares são suas ideias políticas e suas características individuais. A segunda assume que o que determina as escolhas dos parlamentares é o contexto econômico no qual eles estão inseridos. As hipóteses não são mutuamente excludentes, na verdade a expectativa é que as preferências dos parlamentares sejam moldadas por aspectos relacionados aos dois grupos de variáveis, tanto no nível agregado quanto no individual. Sendo assim, nossa expectativa é estimar quanto cada uma delas contribui para que os parlamentares sejam menos ou mais regionalistas, tanto em termos econômicos quanto em termos políticos.

\section{Amostra, dados e estratégias analíticas}

A amostra cobre 17 países da América Latina e os dados são do projeto "Elites latinoamericanas" (Alcántara, 1994-2018). No total, são 1.224 entrevistas realizadas com parlamentares em 17 parlamentos nacionais. Elas ocorreram entre 2011 e 2017. Os dados são referentes às legislaturas mais recentes nesses países. Na Tabela 1, consta uma visão geral da amostra: 
Tabela 1

Países, legislaturas e número de entrevistas realizadas

\begin{tabular}{|l|c|c|c|}
\hline \multicolumn{1}{|c|}{ País } & N $^{\circ}$ entrevistas & Legislatura & Ano \\
\hline Argentina & 67 & $2009-2013$ & 2012 \\
\hline Bolívia & 93 & $2014-2017$ & 2015 \\
\hline Chile & 68 & $2014-2018$ & 2014 \\
\hline Colômbia & 84 & $2014-2018$ & 2014 \\
\hline Costa Rica & 55 & $2014-2018$ & 2014 \\
\hline El Salvador & 58 & $2015-2017$ & 2015 \\
\hline Equador & 88 & $2017-2021$ & 2017 \\
\hline Guatemala & 78 & $2016-2020$ & 2016 \\
\hline Honduras & 82 & $2014-2018$ & 2014 \\
\hline México & 100 & $2015-2018$ & 2016 \\
\hline Nicarágua & 59 & $2017-2022$ & 2017 \\
\hline Panamá & 47 & $2014-2019$ & 2014 \\
\hline Paraguai & 55 & $2013-2018$ & 2013 \\
\hline Peru & 93 & $2011-2016$ & 2011 \\
\hline $\begin{array}{l}\text { República } \\
\text { Dominicana }\end{array}$ & 61 & $2016-2021$ & 2017 \\
\hline Uruguai & 69 & $2015-2020$ & 2015 \\
\hline Venezuela & 67 & $2016-2021$ & 2016 \\
\hline Total & 1.224 & & \\
\hline
\end{tabular}

Fonte: Elaboração dos autores, com dados do Projeto Elites Latinoamericanas (Alcántara, 1994-2018).

Apenas quatro legislaturas (Argentina, Peru, Bolívia e El Salvador) já haviam sido concluídas quando este artigo foi redigido. Elas foram inseridas na amostra porque ainda não existem dados para as legislaturas atuais. Nos demais países, os dados são referentes às legislaturas que estavam em curso quando o presente artigo foi escrito. Para cada legislatura, o questionário é aplicado a uma amostra de deputados estratificada por partidos?.

Os dados utilizados dizem respeito às percepções dos parlamentares sobre questões de política externa. Do amplo questionário aplicado aos parlamentares, foram selecionadas questões relativas às relações internacionais, econômicas e políticas. Elas refletem as preferências dos parlamentares em relação aos países com os quais seu país deveria priorizar relações econômicas e políticas.

Duas estratégias metodológicas foram adotadas: a comparação entre legislaturas/países e a estimação de preditores sobre as opiniões individuais dos parlamentares. A seguir, apresenta-se a análise descritiva comparativa, considerando as opiniões dos parlamentares agregadas por legislatura/país. Estatística descritiva e análise de redes foram utilizadas como estratégias analíticas para comparar as opiniões dos 
parlamentares no nível mais agregado (legislatura/países). E posteriormente estimou-se, a partir de modelos de regressão, a força de alguns preditores sobre as opiniões dos parlamentares. Essa análise no nível individual procura entender fatores determinantes na formação das preferências dos legisladores, controlando por fatores estruturais.

\section{Análise descritiva comparativa}

\section{Relações bilaterais: prioridades econômicas e políticas}

Nesta seção, discutem-se, de forma agregada, as preferências dos parlamentares em relação aos países com os quais eles acham que seu país deveria priorizar as relações econômicas e políticas. Os dados se referem às relações com outros países, portanto, às preferências quanto às relações bilaterais.

Duas questões foram utilizadas para inferir as preferências dos parlamentares nesse ponto, e as perguntas foram formuladas nos seguintes termos: ¿Cuáles son, en su opinión, los tres principales países prioritarios en la política exterior de su país en términos económicos? ¿Y en términos políticos? Foi solicitado ao parlamentar que enumerasse os países por ordem de prioridade ( $1^{\circ}$ lugar, $2^{\circ}$ lugar e $3^{\circ}$ lugar). Um sumário das respostas pode ser visto na Tabela 2.

Os dados mostram que, na opinião dos parlamentares, na maioria das legislaturas os Estados Unidos deveriam ser o país prioritário em termos de relações econômicas. Essa preferência pode ser identificada em 12 dos 17 países analisados. O segundo país que figura entre as primeiras opções dos parlamentares é o Brasil. O Brasil deveria ser prioridade nas relações econômicas para os parlamentares de 4 das 17 legislaturas analisadas.

Ao que tudo indica, parece haver um componente regional influenciando essas escolhas. Note-se que as legislaturas que sugerem a priorização do Brasil são todas dos seus vizinhos da América do Sul: Argentina, Bolívia, Paraguai e Uruguai. Já as preferências pelos Estados Unidos predominam nas legislaturas dos países centro-americanos, embora seja possível observar também sua força no Sul, como nas legislaturas de Colômbia, Peru e Venezuela. 
Tabela 2

Prioridade nas relações bilaterais econômicas e políticas (\%)

\begin{tabular}{|c|c|c|c|c|c|c|}
\hline \multirow{2}{*}{ País } & \multicolumn{3}{|c|}{ Relações econômicas } & \multicolumn{3}{|c|}{ Relações políticas } \\
\hline & $1^{\circ}$ lugar & $2^{\circ}$ lugar & $3^{\circ}$ lugar & $1^{\circ}$ lugar & $2^{\circ}$ lugar & $3^{\circ}$ lugar \\
\hline \multicolumn{7}{|c|}{ América do Sul } \\
\hline Argentina & $\begin{array}{c}\text { Brasil } \\
66,9 \\
\end{array}$ & $\begin{array}{c}\text { China } \\
42,7\end{array}$ & $\begin{array}{c}\text { China } \\
20,7 \\
\end{array}$ & $\begin{array}{c}\text { Brasil } \\
67,9 \\
\end{array}$ & $\begin{array}{l}\text { EUA } \\
27,7\end{array}$ & $\begin{array}{c}\text { China } \\
22,8 \\
\end{array}$ \\
\hline Bolívia & $\begin{array}{c}\text { Brasil } \\
33,4 \\
\end{array}$ & $\begin{array}{c}\text { Argentina } \\
21,9\end{array}$ & $\begin{array}{c}\text { Brasil } \\
12,3 \\
\end{array}$ & $\begin{array}{c}\text { Brasil } \\
23,3 \\
\end{array}$ & $\begin{array}{c}\text { Argentina } \\
18,8 \\
\end{array}$ & $\begin{array}{c}\text { Brasil } \\
10,7 \\
\end{array}$ \\
\hline Chile & $\begin{array}{c}\text { China } \\
40,6\end{array}$ & $\begin{array}{l}\text { EUA } \\
43,7\end{array}$ & $\begin{array}{c}\text { UE } \\
52,3\end{array}$ & $\begin{array}{l}\text { EUA } \\
35,5\end{array}$ & $\begin{array}{c}\text { UE } \\
26,6\end{array}$ & $\begin{array}{l}\text { EUA } \\
17,6\end{array}$ \\
\hline Colômbia & $\begin{array}{l}\text { EUA } \\
68,5 \\
\end{array}$ & $\begin{array}{c}\text { Venezuela } \\
24,5\end{array}$ & $\begin{array}{c}\text { UE } \\
24,0\end{array}$ & $\begin{array}{l}\text { EUA } \\
66,7 \\
\end{array}$ & $\begin{array}{c}\text { UE } \\
20,4\end{array}$ & $\begin{array}{c}\text { UE } \\
28,4\end{array}$ \\
\hline Paraguai & $\begin{array}{c}\text { Brasil } \\
63,0\end{array}$ & $\begin{array}{c}\text { Argentina } \\
48,1\end{array}$ & $\begin{array}{c}\text { Chile } \\
27\end{array}$ & $\begin{array}{c}\text { Brasil } \\
58,5\end{array}$ & $\begin{array}{c}\text { Argentina } \\
49,0\end{array}$ & $\begin{array}{l}\text { EUA } \\
22,2 \\
\end{array}$ \\
\hline Peru & $\begin{array}{l}\text { EUA } \\
35,7 \\
\end{array}$ & $\begin{array}{l}\text { China } \\
30,6\end{array}$ & $\begin{array}{c}\text { Rússia } \\
20,1\end{array}$ & $\begin{array}{l}\text { EUA } \\
40,7 \\
\end{array}$ & $\begin{array}{c}\text { UE } \\
24,3 \\
\end{array}$ & $\begin{array}{c}\text { Brasil } \\
29,9\end{array}$ \\
\hline Uruguai & $\begin{array}{c}\text { Brasil } \\
19,0 \\
\end{array}$ & $\begin{array}{c}\text { China } \\
20,3 \\
\end{array}$ & $\begin{array}{c}\text { UE } \\
32,4 \\
\end{array}$ & $\begin{array}{c}\text { Brasil } \\
19,7 \\
\end{array}$ & $\begin{array}{c}\text { UE } \\
33,5 \\
\end{array}$ & $\begin{array}{l}\text { EUA } \\
37,6 \\
\end{array}$ \\
\hline Venezuela & $\begin{array}{l}\text { EUA } \\
45,4 \\
\end{array}$ & $\begin{array}{c}\text { UE } \\
18,6\end{array}$ & $\begin{array}{c}\text { UE } \\
17,4 \\
\end{array}$ & $\begin{array}{l}\text { EUA } \\
30,1\end{array}$ & $\begin{array}{c}\text { UE } \\
22,4\end{array}$ & $\begin{array}{l}\text { EUA } \\
13,6 \\
\end{array}$ \\
\hline \multicolumn{7}{|c|}{ América do Norte e Central } \\
\hline Costa Rica & $\begin{array}{l}\text { EUA } \\
70,9 \\
\end{array}$ & $\begin{array}{c}\text { UE } \\
35,8\end{array}$ & $\begin{array}{c}\text { UE } \\
26,1\end{array}$ & $\begin{array}{l}\text { EUA } \\
65,5\end{array}$ & $\begin{array}{c}\text { UE } \\
34,0\end{array}$ & $\begin{array}{c}\text { UE } \\
17,8\end{array}$ \\
\hline El Salvador & $\begin{array}{l}\text { EUA } \\
79,2 \\
\end{array}$ & $\begin{array}{c}\text { UE } \\
30,2\end{array}$ & $\begin{array}{c}\text { Brasil/UE } \\
19,6 \\
\end{array}$ & $\begin{array}{l}\text { EUA } \\
76,0 \\
\end{array}$ & $\begin{array}{c}\text { UE } \\
36,7\end{array}$ & $\begin{array}{c}\text { UE } \\
14,6\end{array}$ \\
\hline Equador & $\begin{array}{l}\text { EUA } \\
51,7\end{array}$ & $\begin{array}{c}\text { UE } \\
43,7 \\
\end{array}$ & $\begin{array}{c}\text { UE } \\
22,0 \\
\end{array}$ & $\begin{array}{l}\text { EUA } \\
30,5\end{array}$ & $\begin{array}{c}\text { UE } \\
24,1 \\
\end{array}$ & $\begin{array}{c}\text { UE } \\
24,2 \\
\end{array}$ \\
\hline Guatemala & $\begin{array}{l}\text { EUA } \\
79,7\end{array}$ & $\begin{array}{l}\text { México } \\
25,0\end{array}$ & $\begin{array}{l}\text { México } \\
23,3\end{array}$ & $\begin{array}{l}\text { EUA } \\
76,7\end{array}$ & $\begin{array}{l}\text { México } \\
27,0\end{array}$ & $\begin{array}{c}\text { México } \\
14,8\end{array}$ \\
\hline Honduras & $\begin{array}{c}\text { EUA } \\
59 \\
\end{array}$ & \begin{tabular}{|c|} 
UE \\
27,3 \\
\end{tabular} & $\begin{array}{l}\text { China } \\
25,2\end{array}$ & $\begin{array}{l}\text { EUA } \\
54,4 \\
\end{array}$ & $\begin{array}{c}\text { UE } \\
30,3 \\
\end{array}$ & $\begin{array}{c}\text { China/Brasil } \\
10,8 \\
\end{array}$ \\
\hline México & $\begin{array}{l}\text { EUA } \\
82,1 \\
\end{array}$ & $\begin{array}{c}\text { China/Canadá } \\
27,2 \\
\end{array}$ & $\begin{array}{c}\text { UE } \\
27,1\end{array}$ & $\begin{array}{l}\text { EUA } \\
80,0\end{array}$ & $\begin{array}{c}\text { UE } \\
28,1 \\
\end{array}$ & $\begin{array}{c}\text { UE } \\
27,8\end{array}$ \\
\hline Nicarágua & $\begin{array}{l}\text { EUA } \\
49,8\end{array}$ & $\begin{array}{c}\text { UE/China } \\
14,5\end{array}$ & $\begin{array}{l}\text { China } \\
20,2\end{array}$ & $\begin{array}{c}\text { Venezuela } \\
29,7\end{array}$ & $\begin{array}{c}\text { Venezuela } \\
17,1\end{array}$ & $\begin{array}{c}\text { Bolívia } \\
10,2\end{array}$ \\
\hline Panamá & $\begin{array}{l}\text { EUA } \\
87,2\end{array}$ & $\begin{array}{c}\text { UE } \\
37,8 \\
\end{array}$ & $\begin{array}{c}\text { Colômbia/UE } \\
15,0 \\
\end{array}$ & $\begin{array}{l}\text { EUA } \\
80,9\end{array}$ & $\begin{array}{c}\text { UE } \\
45,5\end{array}$ & $\begin{array}{c}\text { Colômbia } \\
17,6 \\
\end{array}$ \\
\hline \begin{tabular}{|l|} 
República \\
Dominicana
\end{tabular} & $\begin{array}{l}\text { EUA } \\
78,1\end{array}$ & $\begin{array}{l}\text { Haiti } \\
36,6\end{array}$ & $\begin{array}{c}\text { China } \\
18,0\end{array}$ & $\begin{array}{l}\text { EUA } \\
72,2\end{array}$ & $\begin{array}{l}\text { Haiti } \\
27,3\end{array}$ & $\begin{array}{c}\text { UE } \\
17,7\end{array}$ \\
\hline
\end{tabular}

Fonte: Elaboração dos autores com dados do projeto "Elites latino-americanas" (Alcántara, 1994-2018). 
A China aparece como prioridade para a maioria dos parlamentares apenas na legislatura do Chile. A mesma China, entretanto, ocupa lugar de destaque como segunda opção, com preferências mais intensas em 5 dos 17 países, quais sejam: Argentina, Nicarágua, México, Peru e Uruguai. A União Europeia aparece como segunda opção em 6 dos 17 países, o que mostra o forte interesse dos parlamentares latino-americanos nesse bloco econômico, embora seja visto predominantemente como segunda opção. Apesar de não ser um país em si, a União Europeia foi citada por muitos parlamentares como segunda e terceira opções, porque as perguntas são abertas e formuladas sem o auxílio de uma lista de múltipla escolha.

Se observarmos as segundas e terceiras opções, além da presença da China e da União Europeia, alguns países da América Latina começam a aparecer como importantes, em termos econômicos, na percepção dos parlamentares. Entre eles, Argentina, Chile, Colômbia, México e Venezuela. Fora das fronteiras latinas, Canadá e Rússia também aparecem, mas sem maior relevância.

Se compararmos as preferências por relações comerciais com as preferências por relações políticas, vemos que há uma certa correlação entre as duas dimensões da política externa. Dos 17 parlamentos analisados, 8 apresentam estruturas de preferências econômicas e políticas absolutamente iguais. São eles: Bolívia, Costa Rica, El Salvador, Equador, Guatemala, Honduras, Panamá e Venezuela. Em 7 dos casos da amostra, as estruturas de preferências diferem em apenas uma das escolhas e, em alguns casos, apenas na ordem dessas preferências. Os que diferem apenas em uma das escolhas ou apenas na ordem delas são: Argentina, Chile, Colômbia, México, Paraguai, República Dominicana e Uruguai. Somente em dois casos, Nicarágua e Peru, as preferências por relações econômicas se distanciam das preferências por relações políticas.

Esses dados sugerem que, embora preferências políticas e econômicas dos parlamentares estejam associadas, existe uma discrepância entre elas. Os casos discrepantes, provavelmente, reclamam explicações por fatores contextuais (ou conjunturais) relacionados a características específicas dessas legislaturas/países, o que será analisado posteriormente.

De forma resumida, no que se refere a preferências econômicas, pode-se afirmar que existem três aspectos relevantes que resultam, à primeira vista, da análise dos dados. O primeiro é uma preponderância dos Estados Unidos nas preferências comerciais apontadas pelos parlamentares. O segundo é uma clivagem regional, mais especificamente no Sul, que aponta para o Brasil como o parceiro comercial mais relevante para os parlamentares dos seus países vizinhos. O Mercosul, ao que tudo indica, pode ser determinante nas preferências de Argentina, Uruguai, Bolívia e Paraguai em relação ao Brasil. O parlamento do Chile, como um ponto fora da curva, tem deixado clara sua preferência pela China. O terceiro é a presença da União Europeia e da China como importantes parceiros na visão dos parlamentares. 
Os resultados encontram fundamento. O primeiro deles é baseado na força econômica dos Estados Unidos; o segundo, no tamanho da economia do Brasil e, provavelmente, na longa (embora tortuosa) experiência do Mercosul, que aproximou fronteiriços; o terceiro remonta a uma tendência da expectativa por diversificação em termos de relações externas em países do continente asiático, em especial a China.

De toda forma, a variação encontrada no plano agregado (por legislatura) é significativa, o que sugere que fatores estruturais, sejam eles regionais, econômicos ou políticos, provavelmente influenciam a formação das preferências dos parlamentares. Isso chama a atenção para a necessidade de incluir fatores estruturais entre os preditores das preferências individuais, objeto da segunda estratégia analítica (seção "Explorando preditores das preferências dos parlamentares"). Por enquanto, prossegue a análise agregada.

Representação das redes de relações econômicas e políticas na percepção dos parlamentares

Outra forma de representar as preferências dos legisladores quanto às relações bilaterais que seus países deveriam priorizar é a análise de redes, que é baseada em dados relacionais e permite que se estabeleçam representações gráficas dessas relações. $O$ dado relacional aqui utilizado diz respeito a relações bilaterais que "deveriam existir" entre os países, segundo a opinião dos parlamentares.

Embora não se trate de uma rede real, considera-se que o exercício especulativo é válido especialmente em termos exploratórios. Há um ganho analítico com a utilização da análise de redes porque ela permite identificar aspectos importantes que a estatística descritiva não consegue mostrar. A saber, os laços entre múltiplos países, que ficam obscurecidos quando se verificam apenas as opções que aparecem com maiores percentuais em cada unidade de análise agregada (as legislaturas/países).

O Gráfico 1 traz a rede de relações bilaterais econômicas que, na percepção dos parlamentares, deveria ser priorizada, enquanto o Gráfico 2 evidencia a rede de relações bilaterais políticas. Importante frisar que utilizamos nas redes apenas as primeiras opções dos parlamentares.

Os círculos cinza representam os países da amostra, ou seja, nesses países as opiniões dos parlamentares foram ouvidas. Já os círculos pretos representam países que foram citados pelos parlamentares, mas que não fazem parte da amostra. Nesse sentido, as flechas direcionais (laços) que ligam um país a outros (nós) devem ser interpretadas como uma relação pretendida pelos parlamentares no que se refere a esses países. Em poucas palavras, as flechas apontam para os países que representam as preferências dos parlamentares em termos de relações econômicas (Gráfico 1) ou políticas (Gráfico 2). A espessura do laço representa a intensidade da manifestação dessas preferências (número de citações) dos parlamentares por determinado país. Quanto mais espesso o laço, mais parlamentares daquele país manifestaram interesse no país para onde a flecha aponta. 
Há países que estão nas duas situações, ou seja, eles fazem parte da amostra e ao mesmo tempo foram citados pelos parlamentares de outros países como prioridade. Nesses casos a flecha é bidirecional (recíproca). As flechas bidirecionais representam preferências econômicas ou políticas recíprocas entre os parlamentares de dois países. Essa reciprocidade pode não ter (e raramente tem) a mesma intensidade nos dois sentidos. A espessura do laço, portanto, representa a intensidade nas duas direções conjuntamente.

\section{Gráfico 1}

\section{Rede de relações econômicas na percepção dos parlamentares}

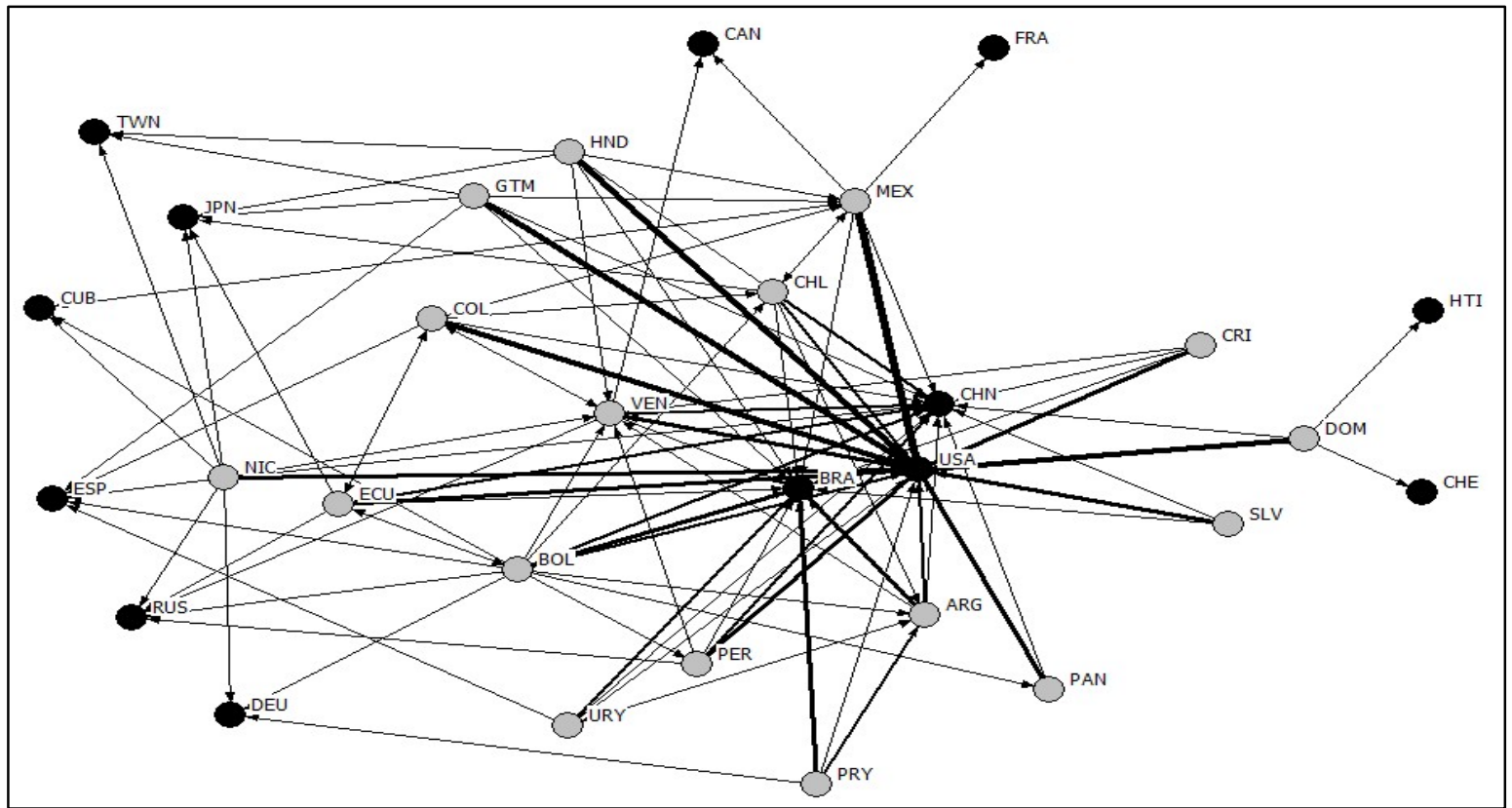

Fonte: Elaboração dos autores, com dados do projeto "Elites latino-americanas" (Alcántara, 1994-2018). 


\section{Gráfico 2}

Rede de relações políticas na percepção dos parlamentares

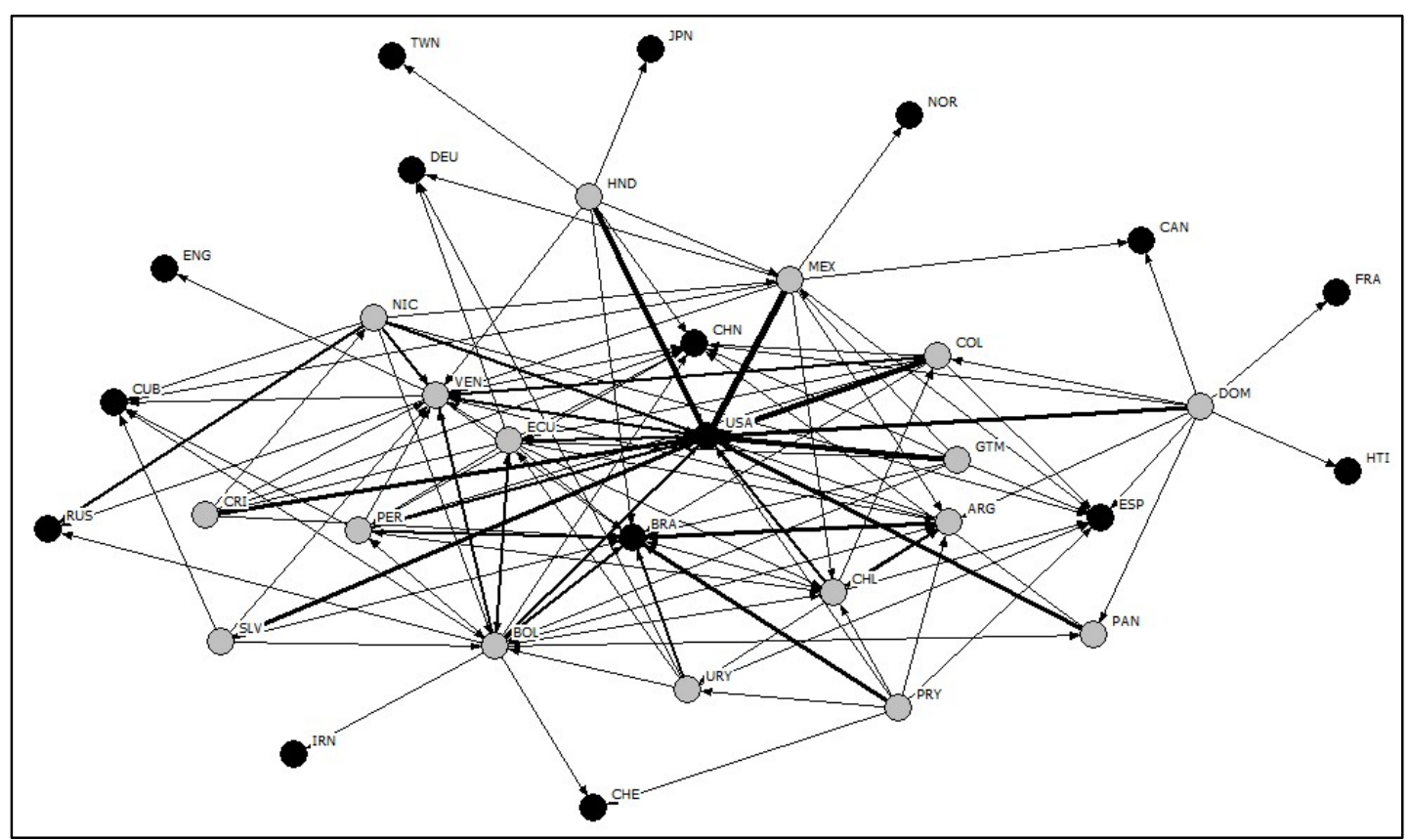

Fonte: Elaboração dos autores, com dados do projeto "Elites latino-americanas" (Alcántara, 1994-2018).

Diferenças importantes podem ser observadas na comparação entre a rede de preferências dos legisladores por relações econômicas e políticas dos seus países, indicando que as preferências por parcerias comerciais e políticas, embora similares, não são a mesma coisa. A primeira diferença entre os Gráficos 1 e 2 está na posição de cada ator na rede. A centralidade na rede é interpretada aqui como um indicador de relevância econômica ou política desse país na percepção dos parlamentares entrevistados.

No centro da rede econômica estão os países que já figuravam como prioridade na análise anterior: Estados Unidos, China e Brasil. Importante frisar que a União Europeia foi retirada dessa análise, já que se trata de um bloco, e não de um país no sentido estrito do termo.

Já na rede política, embora Estados Unidos, China e Brasil continuem com centralidade, a China perde intensidade para o Brasil, em contraste com a rede econômica. Outra novidade é a relevância da Espanha, que não tem destaque na rede econômica. Ademais, é relevante pensar na Venezuela, que parece ter um peso político e econômico superior ao da Argentina e do México, indicando um destaque regional, provavelmente pela questão do petróleo. Por fim, destaca-se o crescimento da importância política da Bolívia.

Outro aspecto importante revelado na análise de redes são as preferências, ainda que secundárias, de parlamentares de alguns países por países europeus e asiáticos, para 
além da China. A posição dos países europeus e asiáticos (à exceção da China) é periférica na rede econômica, mas não parece irrelevante. A Rússia, por exemplo, foi citada por parlamentares de 4 dos 17 países como primeira opção: Peru, Bolívia, Equador e Nicarágua. Já Taiwan foi citado por parlamentares de 3 países: Nicarágua, Guatemala e Honduras. 0 Japão também foi citado como primeira opção por parlamentares de 5 países: Nicarágua, Equador, Chile, Honduras e Guatemala. Na rede política, à exceção da Espanha, a preferência por esses países perde intensidade, o que pode ser visualizado pelo baixo número de conexões.

Para ajudar na visualização da quantidade exata dessas relações, estão reportadas nas Tabelas 3 e 4 algumas medidas da rede que ajudam a interpretar melhor os dados. Nessa rede os países estão organizados em dois blocos. O primeiro bloco é formado pelos países da amostra, ou seja, os países para os quais existem dados sobre as preferências dos parlamentares. Nesse bloco, todos os parlamentares podem citar outros países. Sendo assim, as flechas podem ser tanto unidirecionais (em um ou outro sentido, representando um interesse de um país sobre outro) quanto bidirecionais (o que significa interesse mútuo). No segundo bloco, constam os países que foram citados por parlamentares de outros países, mas sobre os quais não se pode aferir a preferência de seus parlamentares, pois não foram realizadas entrevistas. Nesse bloco, claro, as flechas são sempre unidirecionais e sempre estarão no sentido dos países da amostra para os que não estão na amostra. 
Tabela 3

Medidas descritivas da rede de rede de relações econômicas

\begin{tabular}{|c|c|c|c|c|c|c|c|}
\hline País & OutDeg & Relação & InDeg & País & OutDeg & Relação & InDeg \\
\hline \multicolumn{4}{|c|}{ Países da amostra } & \multicolumn{4}{|c|}{ Países citados } \\
\hline Bolívia & 13 & $\leftrightarrow$ & 1 & Alemanha & 0 & $\leftarrow$ & 3 \\
\hline Nicarágua & 9 & $\rightarrow$ & 0 & Brasil & 0 & $\leftarrow$ & 13 \\
\hline Colômbia & 7 & $\leftrightarrow$ & 2 & Canadá & 0 & $\leftarrow$ & 2 \\
\hline Equador & 7 & $\leftrightarrow$ & 2 & China & 0 & $\leftarrow$ & 16 \\
\hline Guatemala & 7 & $\rightarrow$ & 0 & Cuba & 0 & $\leftarrow$ & 3 \\
\hline Honduras & 7 & $\rightarrow$ & 0 & Espanha & 0 & $\leftarrow$ & 5 \\
\hline México & 7 & $\leftrightarrow$ & 4 & $\begin{array}{l}\text { Estados } \\
\text { Unidos }\end{array}$ & 0 & $\leftarrow$ & 17 \\
\hline Chile & 6 & $\leftrightarrow$ & 3 & França & 0 & $\leftarrow$ & 1 \\
\hline Venezuela & 6 & $\leftrightarrow$ & 8 & Haiti & 0 & $\leftarrow$ & 1 \\
\hline Argentina & 5 & $\leftrightarrow$ & 4 & Japão & 0 & $\leftarrow$ & 5 \\
\hline Peru & 5 & $\leftrightarrow$ & 1 & Rússia & 0 & $\leftarrow$ & 5 \\
\hline Uruguai & 5 & $\leftrightarrow$ & 1 & Suíça & 0 & $\leftarrow$ & 1 \\
\hline Costa Rica & 4 & $\rightarrow$ & 0 & Taiwan & 0 & $\leftarrow$ & 3 \\
\hline El Salvador & 4 & $\rightarrow$ & 0 & & & & \\
\hline Paraguai & 4 & $\rightarrow$ & 0 & & & & \\
\hline R. Dominicana & 4 & $\rightarrow$ & 0 & & & & \\
\hline Panamá & 2 & $\leftrightarrow$ & 1 & & & & \\
\hline
\end{tabular}

Fonte: Elaboração dos autores, com dados do projeto "Elites latino-americanas" (Alcántara, 1994-2018). 
Tabela 4

Medidas descritivas da rede de rede de relações políticas

\begin{tabular}{|c|c|c|c|c|c|c|c|}
\hline Países & OutDeg & Relação & InDeg & Países & OutDeg & Relação & InDeg \\
\hline \multicolumn{4}{|c|}{ Países da amostra } & \multicolumn{4}{|c|}{ Países citados } \\
\hline Bolívia & 13 & $\leftrightarrow$ & 7 & Alemanha & 0 & $\leftarrow$ & 3 \\
\hline Equador & 11 & $\leftrightarrow$ & 4 & Brasil & 0 & $\leftarrow$ & 13 \\
\hline México & 9 & $\leftrightarrow$ & 3 & Canadá & 0 & $\leftarrow$ & 2 \\
\hline R. Dominicana & 9 & $\rightarrow$ & 0 & China & 0 & $\leftarrow$ & 10 \\
\hline Peru & 8 & $\leftrightarrow$ & 3 & Cuba & 0 & $\leftarrow$ & 6 \\
\hline Venezuela & 8 & $\leftrightarrow$ & 10 & Espanha & 0 & $\leftarrow$ & 8 \\
\hline Chile & 7 & $\leftrightarrow$ & 5 & Estados Unidos & 0 & $\leftarrow$ & 16 \\
\hline Guatemala & 7 & $\rightarrow$ & 0 & França & 0 & $\leftarrow$ & 1 \\
\hline Honduras & 7 & $\rightarrow$ & 0 & Haiti & 0 & $\leftarrow$ & 1 \\
\hline Nicarágua & 7 & $\leftrightarrow$ & 1 & Inglaterra & 0 & $\leftarrow$ & 1 \\
\hline Paraguai & 7 & $\rightarrow$ & 0 & Irã & 0 & $\leftarrow$ & 1 \\
\hline Colômbia & 6 & $\leftrightarrow$ & 5 & Japão & 0 & $\leftarrow$ & 1 \\
\hline Uruguai & 6 & $\leftrightarrow$ & 2 & Noruega & 0 & $\leftarrow$ & 1 \\
\hline Costa Rica & 5 & $\leftrightarrow$ & 1 & Rússia & 0 & $\leftarrow$ & 3 \\
\hline El Salvador & 5 & $\rightarrow$ & 0 & Suíça & 0 & $\leftarrow$ & 2 \\
\hline Argentina & 4 & $\leftrightarrow$ & 8 & Taiwan & 0 & $\leftarrow$ & 1 \\
\hline Panamá & 2 & $\leftrightarrow$ & 2 & & & & \\
\hline
\end{tabular}

Fonte: Elaboração dos autores, com dados do projeto "Elites latino-americanas (Alcántara, 1994-2018).

As flechas bidirecionais indicam dupla relação, e os valores da estatística OutDeg indicam quantos países o conjunto de parlamentares de determinado país citou. Já o valor do InDeg indica por quantos países ele foi citado. Valores altos do OutDeg significam que os parlamentares desses países têm preferências por relações bilaterais com muitos outros países. Já os valores altos do InDeg significam que esses países são vistos por muitos outros países como objeto de interesse de relações comerciais, na percepção dos parlamentares.

A título de exemplo, vejamos o caso da Bolívia. Os parlamentares bolivianos demonstram preferências por relações comerciais com 13 dos 17 países contidos na amostra (Tabela 3). Mas esse mesmo país parece não interessar muito, economicamente, aos parlamentares dos países vizinhos. Somente parlamentares do Equador manifestaram ter interesse, como primeira opção, em relações comerciais com a Bolívia. Outro caso interessante é a Venezuela, que aparece como o país com maior valor no InDeg. Nesse caso, esse é o país que desperta o interesse de parlamentares do maior número de países, 8 de 17. A mesma Venezuela, por sua vez, também mostrou ter uma legislatura interessada em múltiplas parcerias econômicas, com valor do OutDeg de 6. 
Em algumas legislaturas, um grande número de países não despertou nenhum interesse econômico, pelo menos não como sua primeira opção. Em 7 dos 17 países, os valores 0 no InDeg podem ser verificados. São eles: Nicarágua, Guatemala, Honduras, Costa Rica, El Salvador, Paraguai e República Dominicana (Tabela 3). Isso sugere que esses países seriam atores isolados na rede de relações comerciais representada com base na opinião dos parlamentares.

Outra diferença entre as preferências econômicas e políticas ganha evidência. Enquanto na rede econômica foram identificados 12 países e 10 relações bidirecionais (Tabela 2), na rede política o número de países citados é ampliado para 16, sendo 12 relações recíprocas (Tabela 3 ). A rede política deveria ser, na percepção dos deputados, mais ampla que a rede econômica. O que faz todo sentido, pois relações políticas não são necessariamente de interesse econômico, embora relações exteriores tenham, em grande medida, como pano de fundo a economia.

Nesse sentido, as diferenças entre as redes reforçam a necessidade de analisar as motivações econômicas e políticas de forma separada. A próxima seção avança na comparação entre os preditores das preferências dos parlamentares quanto às relações regionais, buscando problematizar a interação entre motivações político-ideológicas e pragmáticas na conformação dos esquemas regionalistas econômicos e políticos a partir das preferências dos parlamentares latino-americanos.

\section{Explorando preditores das preferências dos parlamentares}

Os modelos de regressão visam estimar, tendo como unidade de análise o parlamentar, a força de algumas variáveis independentes que possam ser bons preditores para a conformação das suas preferências. Dois modelos são operacionalizados: o modelo 1, tendo como variável dependente um indicador que mede a intensidade das preferências do parlamentar em termos de regionalismo econômico (denominado aqui de RegEcon); e o modelo 2, que tem como variável dependente um indicador similar que mede a intensidade das preferências do parlamentar em termos de regionalismo nas relações políticas (denominado aqui de RegPol).

As variáveis independentes selecionadas estão agrupadas em três blocos. Dois blocos formados com variáveis no nível agregado, por país, que visam estimar se aspectos do contexto econômico do país no qual o parlamentar está inserido são determinantes para a conformação de suas preferências. E um bloco de variáveis no nível individual do parlamentar, que visa estimar se as características político-ideológicas são bons preditores na conformação de suas preferências. Algumas variáveis de controle também foram inseridas. 
Variáveis dependentes: operacionalização

O modelo 1 tem como variável dependente um índice de regionalismo econômico, aqui denominado RegEcon. O RegEcon mede o valor agregado das preferências do parlamentar por relações bilaterais com países da região. O indicador é calculado a partir da agregação das preferências por relações bilaterais, considerando as três opções ordenadas pelos parlamentares. Como o dado é resultado de uma pergunta aberta, que permite ao parlamentar listar três países, e as respostas são relacionadas a países específicos, as variáveis foram recodificadas de forma binária, recebendo valor 1 para os casos nos quais foram citados países latino-americanos e 0 para países que não são dessa região. Considerando, também, que as preferências são ordenadas em primeira, segunda e terceira opções, uma ponderação foi utilizada para dar mais peso às respostas citadas preferencialmente. Sendo assim, a primeira opção recebe valor 3, a segunda, valor 2 e a terceira, valor 1 . Se o parlamentar cita um país não latino-americano, ele recebe valor 0 . A escala do RegEcon, portanto, vai de 0 a 6 . Um parlamentar receberá valor 0 se não citar nenhum país da região em nenhuma das três opções e receberá valor 6 , máximo, se citar nas três opções países latino-americanos.

O RegEcon deve ser interpretado da seguinte forma: quanto mais alto for o valor recebido pelo parlamentar nesse índice, mais fortes serão suas preferências por relações econômicas com países da região. Em suma, um indicador que mede a intensidade de sua preferência regionalista.

O modelo 2 tem como variável dependente um índice de regionalismo político, aqui denominado RegPol. O RegPol mede o valor agregado das preferências do parlamentar por relações políticas bilaterais com países da região. O indicador é calculado da mesma forma que o RegEcon, mas, claro, usando as respostas para as relações políticas. O RegPol deve ser interpretado da seguinte forma: quanto mais alto for o valor recebido pelo parlamentar nesse índice, mais fortes serão suas preferências por relações políticas com países da região.

A Tabela 5 mostra as estatísticas descritivas dos dois indicadores. O primeiro resultado relevante já se pode ver nas medidas de tendência central. Note-se que os parlamentares latino-americanos têm preferências regionais mais intensas em termos políticos do que em termos econômicos. É o que se pode observar comparando a média e a mediana dos dois indicadores. A diferença entre as médias é de 0,76 em favor do regionalismo político, e a diferença da mediana é de 2,0 entre as duas variáveis, numa escala que varia de 0 a 6. 
Tabela 5

Medidas de tendência central e dispersão das variáveis dependentes

\begin{tabular}{|l|c|c|c|c|}
\hline Indicador & Média & Mediana & Variância & Desvio-padrão \\
\hline RegEcon & 1,79 & 1,0 & 3,485 & 1,865 \\
\hline RegPol & 2,56 & 3,0 & 4,047 & 2,012 \\
\hline
\end{tabular}

Fonte: Elaboração dos autores, com dados do projeto "Elites latino-americanas" (Alcántara, 1994-2018).

As medidas de dispersão também nos ajudam a entender essas diferenças. Note-se que tanto a variância quanto o desvio-padrão são bem diferentes na comparação entre as duas variáveis. As estatísticas sugerem que, entre os respondentes, há uma dispersão menor quanto às suas preferências por regionalismo econômico do que quanto às suas preferências por regionalismo político. Isso, de fato, é esperado, dado o caráter mais pragmático relacionado às escolhas econômicas.

A correlação de Pearson entre os dois indicadores é de 0,527 (Pvalor $=0,000$ ), que pode ser considerada uma correlação forte, mas isso não desautoriza tratá-los como indicadores com certo grau de independência. Os dois indicadores comparados parecem realmente sugerir que existem diferenças nas preferências dos parlamentares quando se trata de escolher com quem seu país deve se relacionar em termos políticos e econômicos. Considerando as diferenças entre as médias, tudo leva a crer que os parlamentares estão dispostos a abrir mão do ideal regionalista quando se trata de relações econômicas.

A distribuição das preferências nas duas variáveis também pode ser visualizada nos histogramas dos Gráficos 3 e 4. Note-se que as duas apresentam comportamentos bastante distintos. A variável RegEcon tem valores inflacionados em 0 , enquanto a variável RegPol tem valores inflacionados em 3 , que é um valor mais para o centro da escala, na direção de preferências mais fortes por regionalismo. 
Gráfico 3

Histograma RegEcon

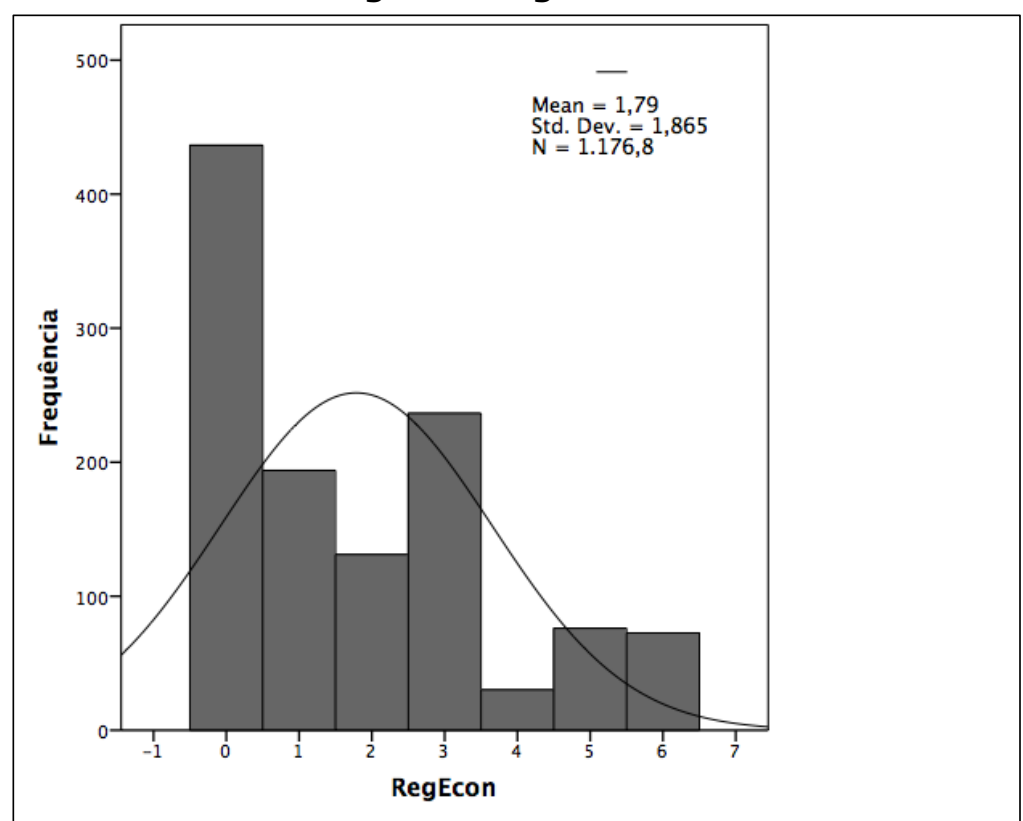

Fonte: Elaboração dos autores, com dados do projeto "Elites latino-americanas" (Alcántara,1994-2018).

Gráfico 4

Histograma RegPol

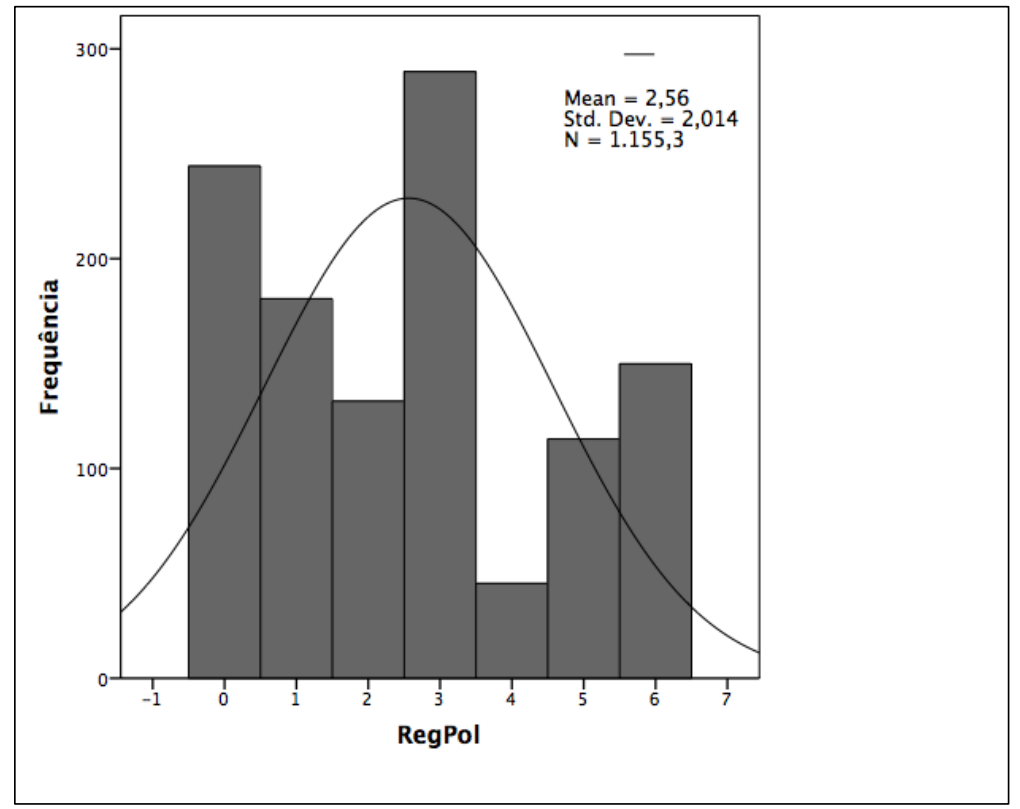

Fonte: Elaboração dos autores, com dados do projeto "Elites latino-americanas" (Alcántara,1994-2018). 
Em comum entre essas variáveis, temos a assimetria à esquerda. O que já pôde ser de alguma forma antecipado quando foram discutidos os valores das médias e medianas, que estão abaixo dos valores intermediários na escala. Esses diferentes comportamentos têm duas implicações para os modelos de regressão em foco. A primeira é que, por terem comportamentos distintos, há um reforço da ideia de que elas captam realmente duas dimensões bem diferentes das preferências dos parlamentares. A segunda é que, como nenhuma das duas distribuições cumpre o pressuposto da distribuição normal, talvez seja prudente também aplicar modelos lineares generalizados, a título de comparação com modelos lineares simples. Optou-se por controlar os resultados comparando as regressões lineares com modelos do tipo Gama Log, que tem função de ligação apropriada para lidar com esse tipo de distribuição.

\section{Variáveis independentes}

Para os dois modelos, com variações pontuais, teremos variáveis independentes em dois níveis. No nível individual do parlamentar e no nível agregado por país/legislatura. A ideia é verificar em que medida as preferências dos parlamentares podem ser preditas pelas suas preferências individuais, controladas por variáveis políticas, institucionais e econômicas que caracterizam os diferentes contextos nos quais eles estão inseridos.

No nível agregado, foram incluídas três variáveis, que estamos denominando de variáveis de contexto. São elas: mercosul (se o parlamentar faz parte de um país membro do Mercosul - dummy); al_pacif (se o parlamentar faz parte de um país membro da Aliança do Pacífico - dummy); alba (se o parlamentar faz parte de um país membro da Aliança Bolivariana para os Povos de Nossa América - Tratado de Comércio dos Povos - dummy).

A hipótese geral relacionada a essas variáveis de contexto é a seguinte: o fato de um país já fazer parte de um tratado regional, seja ele com ambições de ampla integração (Mercosul e Alba) ou mais voltado para interesses econômicos (como a Aliança do Pacífico), deve afetar as preferências dos parlamentares. Parte-se da premissa de que a trajetória trilhada por esses países deixa um "legado de regionalismo" nos parlamentos. Afinal, todos esses acordos passam pela apreciação das casas legislativas, informando e qualificando o debate entre os parlamentares. Ademais, uma vez engajados num acordo regional, os parlamentos desses países passam a conviver com suas consequências (positivas e negativas) e com os dilemas políticos e econômicos no cotidiano de seus debates. Não raro, esses parlamentos precisam deliberar sobre vários aspectos relacionados a esses acordos. A hipótese aqui formulada aposta que esse legado de regionalismo, derivado da filiação prévia do país a um acordo regional, deve influenciar positivamente a opinião dos parlamentares, levando-os a ser mais regionalistas. Tanto em termos políticos como econômicos.

Ainda no nível agregado, três outras variáveis foram incluídas. Estamos denominando esse bloco de variáveis de pragmatismo econômico. A primeira, abertura_com (calculada como: exportações + importações/PIB), mede a exposição do país ao comércio 
internacional, indicando o grau de dependência dos produtores nacionais em relação ao mercado externo, bem como dos consumidores domésticos em relação a produtos estrangeiros. A segunda variável, manufat_PIB (calculada como: importações de bens manufaturados/PIB), mede o grau de dependência do mercado interno em relação a produtos manufaturados. Esse indicador pode ser utilizado como proxy do grau de desenvolvimento do parque industrial nacional. Finalmente, a terceira variável, conc_mercado, refere-se ao "Indicador de Concentração de Mercado Herfindahl-Hirschman", que mensura a dispersão do volume de exportação do país entre os parceiros comerciais. Quanto mais concentrado for o destino da exportação (poucos parceiros comerciais), maior a dependência do país em relação a um número restrito de parceiros. Nesse caso, o valor do indicador será mais próximo a 1 . Por sua vez, quanto maior a diversificação do destino das exportações, o indicador de concentração será mais próximo a $0^{8}$.

As hipóteses aqui formuladas sugerem que as preferências dos parlamentares, mais ou menos regionalistas, também são influenciadas por razões pragmáticas. Ou seja, especula-se que o parlamentar leva em conta o cenário real das relações econômicas internacionais do seu país na conformação de suas preferências. As hipóteses específicas para cada variável de pragmatismo econômico são as que seguem.

Para a primeira variável, abertura_com, espera-se uma correlação negativa entre o grau de abertura comercial e a intensidade de preferência dos parlamentares por regionalismo econômico. Isso porque, quanto maior a exposição da economia doméstica em relação ao comércio internacional, maiores os incentivos para que o país construa redes de relações econômicas que extrapolem a região.

Já para a segunda variável, manufat_PIB, espera-se uma correlação positiva entre o grau de dependência do mercado interno em relação a produtos manufaturados e as preferências por regionalismo, tanto no nível econômico quanto no político. A explicação para essa expectativa advém da própria trajetória de industrialização tardia da região, que a coloca em uma situação de elevada dependência da importação de produtos de maior valor agregado, oriundos das economias desenvolvidas. A competição com produtos importados gera constrangimentos para os produtores nacionais, criando incentivos para maior aproximação com os países da região como forma de alcançar maior autonomia industrial.

Nesse sentido, o peso do comércio internacional em relação ao PIB gera constrangimentos e incentivos distintos. Por um lado, a maior exposição ao comércio sugere maior distanciamento em relação à região, por outro lado, a maior dependência em relação à importação de manufaturas sugere maior aproximação. Espera-se que essa estrutura de constrangimentos e incentivos influencie pragmaticamente as preferências econômicas e políticas dos parlamentares em relação ao regionalismo.

${ }^{8}$ As especificações e detalhes sobre a operacionalização dessas variáveis podem ser encontrados no Anexo I. 
Finalmente, quanto à variável de conc_mercado, não se tem uma expectativa de saída. Nenhuma hipótese teórica ou empiricamente orientada. A sua inclusão foi motivada mais como forma de variável de controle.

A Tabela 6 traz a distribuição dos países da amostra considerando sua participação em tratados de integração regional, variáveis de contexto e os números relativos aos indicadores de comércio internacional, agrupados em torno da ideia de pragmatismo econômico:

\section{Tabela 6}

Participação em tratados de livre-comércio e grau de abertura comercial

\begin{tabular}{|c|c|c|c|c|c|c|}
\hline \multirow[b]{2}{*}{ País } & \multicolumn{3}{|c|}{$\begin{array}{c}\text { Participação em blocos } \\
\text { regionais }\end{array}$} & \multicolumn{3}{|c|}{$\begin{array}{l}\text { Indicadores de comércio } \\
\text { internacional }\end{array}$} \\
\hline & Mercosul & $\begin{array}{c}\text { Aliança do } \\
\text { Pacífico }\end{array}$ & Alba & $\begin{array}{c}\text { Grau de } \\
\text { Abertura }\end{array}$ & $\begin{array}{c}\text { Manufatura } \\
\text { PIB }\end{array}$ & $\begin{array}{c}\text { Concentração } \\
\text { do Mercado }\end{array}$ \\
\hline Argentina & Sim & & & 34,08 & 11,50 & 0,06 \\
\hline Bolívia & & & Sim & 79,28 & 26,07 & 0,18 \\
\hline Chile & & Sim & & 70,27 & 19,28 & 0,09 \\
\hline Colômbia & & Sim & & 36,78 & 12,47 & 0,16 \\
\hline Costa Rica & & & & 71,42 & 28,99 & 0,13 \\
\hline Equador & & & Sim & 61,05 & 20,01 & 0,17 \\
\hline El Salvador & & & & 70,59 & 26,75 & 0,28 \\
\hline Guatemala & & & & 61,14 & 23,05 & 0,21 \\
\hline Honduras & & & & 116,97 & 38,06 & 0,35 \\
\hline México & & Sim & & 61,61 & 22,07 & 0,53 \\
\hline Nicarágua & & & Sim & 103,69 & 36,04 & 0,34 \\
\hline Panamá & & & & 144,84 & 42,89 & 0,07 \\
\hline Paraguai & Sim & & & 100,38 & 39,03 & 0,08 \\
\hline Peru & & Sim & & 52,77 & 15,88 & 0,08 \\
\hline $\begin{array}{l}\text { República } \\
\text { Dominicana }\end{array}$ & & & & 57,02 & 18,11 & 0,35 \\
\hline Uruguai & Sim & & & 54,72 & 15,07 & 0,07 \\
\hline Venezuela & $\operatorname{Sim}^{1}$ & & Sim & 48,47 & 7,89 & 0,30 \\
\hline
\end{tabular}

Fonte: Elaboração dos autores com base nos sites oficiais dos blocos regionais ${ }^{9}$.

${ }^{1}$ A Venezuela encontra-se suspensa do bloco.

Consideradas as variáveis do nível agregado, passa-se a discutir as variáveis no nível individual. Nesse nível, foram incluídas duas variáveis, uma política e outra econômica: ideologia (mensurada pelo autoposicionamento do parlamentar numa escala de 1 a 10, em que 1 é totalmente esquerda e 10, totalmente direita); estado_mercado, que mede as

${ }_{9}^{9}$ Disponível em: <https://www.mercosur.int/> ; <https://alianzapacifico.net/>; <http://alba-tcp.org/>. Acesso em: 11 nov. 2020. 
preferências do parlamentar em relação à presença do Estado na economia (mensurada numa escala de 1 a 10, em que 1 é forte presença do Estado na economia e 10, nenhuma presença do Estado na economia).

A hipótese geral sugere que a formação das preferências dos parlamentares sobre regionalismo, tanto político quanto econômico, é influenciada pelas ideias políticas. Sendo assim, a orientação ideológica do parlamentar (esquerda-direita) e suas preferências pela presença maior ou menor do Estado na economia (estado_mercado) devem estar correlacionadas com as variáveis dependentes. A hipótese, portanto, é formulada nos seguintes termos: quanto mais à direita no espectro ideológico e quanto mais intensas forem suas preferências por uma economia regulada pelo mercado, menos regionalistas devem ser as preferências dos parlamentares.

As variáveis ideologia e estado_mercado estão correlacionadas, o que faz todo sentido teórico. A correlação de Pearson entre os dois indicadores é positiva, e com coeficiente de 0,508 (Pvalor $=, 000$ ). Parlamentares mais à direita no espectro ideológico também apresentam preferências mais intensas por uma economia menos regulada pelo Estado. Mas há razões para incluí-las separadamente no modelo. A primeira é que, como se vê, a correlação não é tão forte assim, e nossa interpretação para o dado é que na América Latina os parlamentares liberais (assim como os empresários) não são exatamente modelos de liberalismo econômico clássico. Estado mínimo e economia regulada pelo mercado, no sentido clássico do termo, não são características muito intensas entre nossas elites econômicas e políticas. Acreditamos que isso se dá, em boa medida, pelo papel histórico determinante que o Estado teve, e continua tendo, no desenvolvimento econômico da região. O que se nota é que há um certo "apreço generalizado pelo Estado" entre as elites parlamentares da região. Isso se pensarmos em termos comparativos com as opiniões políticas em economias desenvolvidas e fortemente orientadas pelo princípio liberal.

A segunda razão para incluir separadamente essas variáveis diz respeito à formulação das hipóteses, que são diferentes entre si. No que diz respeito à ideologia, espera-se que, quanto mais à direita no espectro ideológico, menos regionalistas sejam os parlamentares. Mas acredita-se que, por ser uma variável eminentemente política, ela tenha maior capacidade explicativa sobre a formação das preferências por regionalismo político que sobre a formação daquelas relacionadas a regionalismo econômico.

Com relação à variável estado_mercado, segundo nossa hipótese, devemos esperar que, quanto mais favorável a uma economia regulada pelo mercado, menos regionalista seja o parlamentar. Dito de forma mais direta, espera-se que, quanto mais favorável a uma economia regulada pelo mercado, menos os parlamentares estariam dispostos a aceitar que o Estado determine, com sua política de relações internacionais, com quem o empresariado nacional deveria manter relações econômicas. Isso porque acordos regionais são manufaturas predominantemente produzidas por governos. Esses acordos são, por definição, políticas de Estado e com forte viés de esquerda. Mas nesse caso, ao contrário da ideologia, 
esperamos um efeito maior dessa variável sobre a formação das preferências em termos econômicos do que sobre a formação daquelas relacionadas a regionalismo político.

Assim, embora o sentido da influência dos dois indicadores seja esperado na mesma direção (negativa, no caso), parece justificável pensar que eles apresentem intensidades de efeitos diferentes sobre as duas variáveis dependentes aqui consideradas.

Variáveis de controle

A título de controle, foram incluídas três variáveis relacionadas ao mandato do parlamentar e ao seu background. São elas: seniority, que mede o tempo do parlamentar no exercício do mandato (o valor é medido pelo número de mandatos do parlamentar, numa escala de 1 a 3 ou mais mandatos); oposição, que determina se o parlamentar se considera de oposição ao governo (com valor 1 para parlamentares de oposição e 0 para os que se declararam do governo ou independentes - dummy); businessman, que determina a principal ocupação do parlamentar, além da atividade legislativa (com valor 1 para os parlamentares empresários ou ligados a negócios e 0 para demais ocupações - dummy).

Também a título de controle, três variáveis sociodemográficas foram incluídas, tais como: grau_de_instrução (que varia numa escala de 1 a 6 , sendo que o valor mais alto retrata o parlamentar com estudos de pós-graduação); estudo_no_exterior (uma dummy com valor 1 para o parlamentar que estudou no exterior e 0 em caso negativo); feminino, que designa o gênero do parlamentar ( 0 para masculino, 1 para feminino). Não há hipóteses teóricas ou expectativas empíricas para a relação entre essas variáveis e as variáveis dependentes; elas foram incluídas apenas como controles.

\section{Resultados}

$\mathrm{Na}$ Tabela 7, estão reportados os resultados dos modelos de regressão. Na coluna $\beta$, o $\beta$ da regressão, na seguinte o $\beta$ padronizado e, por fim, o Pvalor. Os modelos 1 e 2 têm como variáveis dependentes, respectivamente, os índices de regionalismo econômico e político.

Em relação às variáveis de contexto, a hipótese relacionada à força do "legado de regionalismo" nos parlamentos, derivado da filiação prévia do país a um acordo regional, resta confirmada nos dois modelos. De fato, se os parlamentares fazem parte de um país que é membro de acordos regionais, isso aumenta a probabilidade, em média, de esses parlamentares terem preferências mais intensas, por regionalismo tanto econômico quanto político. Note-se que todos os coeficientes são positivos e estatisticamente significativos, à exceção da variável al_pacif no modelo 1 (regionalismo econômico). O Pvalor para essa variável no modelo 1 é de 0,232, e, sendo assim, não se pode rejeitar a hipótese nula de que elas não estão associadas. Esse resultado é bastante coerente, pois, de fato, a Aliança do Pacífico é um acordo regional diferente dos demais. Sabe-se que os parceiros comerciais 
desse acordo têm o foco na exportação para países asiáticos. Nesse sentido, embora o pertencimento à Aliança do Pacífico ajude a entender a formação das preferências políticas (modelo 2), ela não tem relevância, pelo menos em termos de significância estatística, para explicar as preferências dos parlamentares por regionalismo econômico.

Tabela 7

Regressão regionalismo econômico e político

\begin{tabular}{|c|c|c|c|c|c|c|}
\hline \multirow[b]{2}{*}{ Variáveis } & \multicolumn{3}{|c|}{$\begin{array}{c}\text { Modelo } 1 \\
\text { Regionalismo econômico (vd) }\end{array}$} & \multicolumn{3}{|c|}{$\begin{array}{c}\text { Modelo } 2 \\
\text { Regionalismo político (vd) }\end{array}$} \\
\hline & $\beta$ & $\beta \_$pad & Pvalor & $\beta$ & $\beta \_$pad & Pvalor \\
\hline (Constant) & 2,483 & &, 000 & 3,623 & & 000 \\
\hline \multicolumn{7}{|l|}{ Variáveis de contexto } \\
\hline mercosul & 1,958 & ,438 &, 000 & 1,286 & ,269 &, 000 \\
\hline al_pacif & ,189 &, 044 & ,232 & 697 & 149 &, 000 \\
\hline alba & ,338 & ,079 &, 017 & 816 & 178 & ,000 \\
\hline \multicolumn{7}{|c|}{ Pragmatismo econômico } \\
\hline abertura_com &,- 033 &,- 460 &, 000 &,- 012 &,- 160 &, 060 \\
\hline manufat_PIB & 128 &, 660 & ,000 & 065 &, 313 & ,001 \\
\hline conc_mercado & $-1,593$ &,- 116 & ,000 & $-2,822$ &,- 192 & ,000 \\
\hline \multicolumn{7}{|c|}{$\begin{array}{l}\text { Preferências políticas e } \\
\text { econômicas }\end{array}$} \\
\hline ideologia &,- 098 &,- 129 &, 000 &,- 147 &,- 180 &, 000 \\
\hline estado_mercado &,- 079 &,- 108 &, 001 &,- 078 &,- 099 &, 003 \\
\hline \multicolumn{7}{|l|}{ Controles } \\
\hline businessman &, 075 &, 016 &, 546 &,- 200 &,- 041 &, 150 \\
\hline seniority &, 000 &, 000 & ,996 &,- 054 &,- 021 & ,460 \\
\hline oposição &,- 054 &,- 014 &, 626 &,- 233 &,- 058 & ,057 \\
\hline grau_de_instrução &,- 153 &,- 078 &, 007 &,- 095 &,- 045 &, 136 \\
\hline estudo_no_exterior & 204 &, 045 & 109 &, 085 & ,018 & 548 \\
\hline feminino & ,096 & ,023 & ,394 &, 042 & ,009 & ,738 \\
\hline Ajuste dos modelos & \multicolumn{3}{|c|}{$\begin{array}{l}\mathrm{N}=1.066 \\
\mathrm{R}^{2}=0,280\end{array}$} & \multicolumn{3}{|c|}{$\begin{array}{l}N=1.052 \\
R^{2}=0,227\end{array}$} \\
\hline
\end{tabular}

Fonte: Elaboração dos autores, com dados do projeto "Elites latino-americanas" (Alcántara, 1994-2018) e dos sites oficiais dos blocos regionais.

É justo que se possa argumentar que existe uma endogeneidade em relação a essas variáveis no modelo. Ou seja, o fato de pertencer a essas alianças molda as preferências dos parlamentares ou seria, num sentido contrário, o resultado dessas preferências? Em defesa da manutenção dessas variáveis no modelo, argumenta-se em duas vias. Primeiro, dado o contexto de presidencialismo de coalizão, em termos de política externa, os parlamentos têm um papel mais reativo que propositivo nesses assuntos. Sabe-se que as iniciativas de política 
externa e de integração regional são políticas capitaneadas pelo Poder Executivo. No contexto da América Latina, fala-se com frequência no termo diplomacia presidencial. Sendo assim, o papel do parlamento seria muito mais o de reagir às proposições do Executivo que propriamente o de formular e pôr em marcha a política externa. Segundo, se existe alguma endogeneidade, ela se vê fortemente desafiada pelo fato de a Aliança do Pacífico não apresentar significância estatística para explicar o regionalismo econômico. Nesse sentido, vale argumentar que não se trata de endogeneidade, senão da identidade dos acordos em análise. Fala-se, hoje, por exemplo, da inclusão do Canadá e da Austrália na Aliança do Pacífico, o que dá a esse acordo uma identidade bastante diferente dos demais. Por outro lado, a variação nos coeficientes estimula a manutenção dessas variáveis no modelo.

Mas, no geral, a hipótese do "legado regionalista" se sustenta de maneira bastante convincente, segundo os resultados aqui apresentados. Contudo, é importante registrar que os diferentes acordos regionais afetam as preferências econômicas e políticas com intensidade bastante diversificada.

A análise dos coeficientes ajuda a entender melhor essas diferenças. Note-se que os coeficientes padronizados ( $\beta$ padronizado) mostram que os acordos têm, entre si, diferenças relevantes na sua força explicativa. A variável mercosul apresenta os valores mais altos, seguida das variáveis alba e al_pacif, com os valores mais tímidos. E isso vale tanto para o regionalismo econômico quanto para o regionalismo político. Para interpretar de forma mais direta esse resultado, é suficiente a verificação do coeficiente $\beta$, nesse caso o não padronizado. O resultado mostra que, para os parlamentares dos países que fazem parte do Mercosul, devemos esperar, em média, um aumento de 1,958 na escala de regionalismo econômico e de 1,286 na escala de regionalismo político. Se considerarmos que essa escala varia de 1 a 6, como já discutido anteriormente, deve-se entender que esse impacto é realmente de grande monta. Ao se verificar os outros coeficientes, vê-se que o Mercosul é o acordo regional que impacta mais fortemente na formação da opinião dos parlamentares dos países que fazem parte dele. Esse resultado também pode ser explicado pela importância que o Mercosul tem para Argentina, Uruguai, Paraguai e Venezuela em função do mercado brasileiro.

Ainda no bloco das variáveis de contexto, outro dado chama a atenção. Note-se que o $\beta$ padronizado do mercosul é maior no modelo para preferências econômicas $(0,438)$ que no modelo para regionalismo político $(0,269)$. Pensando em termos comparativos, pode-se afirmar que a variável mercosul induz mais fortemente a formação de preferências por regionalismo econômico que por regionalismo político. Ademais, a inspeção dos dados mostra que isso só acontece com o Mercosul. Note-se que o $\beta$ padronizado da variável alba é maior no modelo que explica as preferências políticas $(0,178)$ que no modelo para as preferências econômicas $(0,079)$, o que inverte a lógica do resultado entre os dois acordos. A interpretação desse resultado pode ser feita à luz das diferenças entre os acordos aqui comparados. O Mercosul, além de mais antigo, hoje já apresenta resultados econômicos concretos bastante significativos se comparado com a Alba. Nesse sentido, parece coerente 
que essa variável explique mais as preferências por regionalismo econômico que as preferências por regionalismo político, embora a força explicativa do Mercosul seja observada nos dois modelos. Por outro lado, a Alba, além de mais recente, tem conteúdo político bem mais acentuado que o Mercosul. A Alba foi constituída num contexto de acordos entre Venezuela e Cuba, ambos com governos de esquerda, e motivada por um ideal de integração latino-americana com forte acento ideológico. Mais que um acordo econômico, afirmam seus documentos fundadores, trata-se de uma ideia de cunho político-ideológico fortemente ancorada no pensamento da cooperação entre as nações, baseada nos ideais bolivarianos. Por fim, os valores tímidos, pelo menos em termos comparativos, da variável Aliança do Pacífico ajudam a entender as diferenças entre a força explicativa das variáveis de contexto.

Passando às variáveis do bloco de pragmatismo econômico, vemos que o peso do comércio internacional no PIB dos países também apresentou resultado significativo, corroborando nossas hipóteses tanto em relação à abertura econômica quanto em relação à dependência da manufatura. Interessante observar, no entanto, que o indicador de abertura econômica se mostrou significativo apenas para o modelo 1 e esse resultado pode ser explicado pelo fato de que a maior exposição ao comércio internacional cria incentivos para a ampliação das relações econômicas para além da região, mas não interfere na percepção do parlamentar a respeito das relações políticas. Já a dependência da manufatura apresentou resultado negativo e significativo em ambos os modelos, tendo obtido o valor mais elevado do $\beta$ padronizado. Isso significa que, em comparação com as demais variáveis do modelo, a dependência da manufatura é a variável que mais interfere na preferência dos parlamentares em favor do regionalismo.

Esse resultado aponta para uma questão crucial em relação às razões econômicas que motivam o regionalismo na América Latina. Ao longo do tempo, a região tem buscado, sem sucesso, o aumento da sofisticação de seu parque industrial para fazer frente à competição com os produtos importados. Mais importante, essa autonomia é percebida como caminho para a superação do atraso econômico, no sentido de proporcionar a transformação da base estrutural dessas economias e o aumento de renda para os trabalhadores. No entanto, a liberalização econômica e, especificamente, a intensificação dos fluxos comerciais com economias desenvolvidas têm levado, historicamente, ao aumento da especialização das economias latino-americanas em produtos de baixo valor agregado. Desse modo, a maior dependência em relação às importações de bens manufaturados parece sensibilizar os parlamentares no sentido de intensificar as suas preferências por parceiros regionais, tanto no plano econômico quanto no político.

Já o indicador de concentração de mercado apresentou resultado negativo e estatisticamente significativo em ambos os modelos. Como não tínhamos uma hipótese de saída, o resultado encontrado nos permite formular a proposição de que, quanto maior a concentração das exportações em poucos parceiros, menor a preferência pelo regionalismo. A explicação para isso pode estar no fato de que um país com poucos parceiros comerciais aumenta os incentivos para a diversificação das exportações para além da região. Por isso, 
a concentração de mercado favorecia uma percepção mais aberta em relação a outras regiões. Mas essa é uma especulação que precisa de estudos mais aprofundados.

Finalmente, os resultados para as variáveis no nível individual, relativas às preferências políticas e econômicas dos parlamentares, também corroboram as hipóteses aqui formuladas. As duas variáveis, ideologia e estado_mercado, apresentaram significância estatística nos dois modelos, permitindo inferências baseadas na rejeição da hipótese nula, segundo a qual elas não estariam correlacionadas. Isso quer dizer que, quanto mais à direita do espectro ideológico se autoposicionam os parlamentares, menor a probabilidade de eles serem mais regionalistas, em média. E isso tanto em termos econômicos (modelo 1) quanto em termos políticos (modelo 2).

Mais uma vez, a interpretação do $\beta$ (nesse caso o não padronizado) ajuda a entender melhor os resultados. Essa interpretação pode ser feita de forma direta sobre a correlação entre as variáveis independentes e as dependentes. Isso significa que, em termos absolutos, com o incremento de 1 ponto na escala ideológica esquerda-direita (que vai de 1 a 10), deve-se esperar uma diminuição, em média, de -0,098 no índice de preferências por regionalismo econômico dos parlamentares e de $-0,147$ no índice de regionalismo político.

Resultado semelhante se observa, tal como hipotetizado, para a relação entre a variável independente estado_mercado e as variáveis dependentes de, respectivamente, RegEcon e RegPol. No primeiro caso, com o incremento de 1 ponto na escala que mede as preferências dos parlamentares por estado_mercado (que varia de 1 a 10), deve-se esperar uma diminuição de $-0,079$, em média, no índice de regionalismo econômico e de $-0,078$ no índice de regionalismo político.

A análise do $\beta$ padronizado completa o quadro interpretativo da força explicativa dessas variáveis, em termos comparativos, sobre a formação das preferências dos parlamentares em termos de regionalismo econômico e político. Interessante registrar que, no caso do modelo 1 (regionalismo econômico), as duas variáveis apresentam $\beta$ padronizados bastante semelhantes, o que aponta para uma relativa equivalência entre elas. Os valores são de -0,129 para ideologia e -0,108 para estado_mercado. Essa semelhança, entretanto, desaparece no modelo 2 . Nesse caso, a variável ideologia tem o valor de $-0,180$ e a variável estado_mercado, o valor de -0,099. No modelo 2, como se pode ver na Tabela 7, a força da variável ideologia é quase o dobro da apresentada pela variável estado_mercado.

Ao final, o resultado como um todo é certamente bastante coerente, visto que devemos esperar que variáveis políticas, como as preferências ideológicas, tenham de fato mais força sobre a explicação do modelo que tem como variável dependente o regionalismo político. E é possível ver claramente que os dados confirmam essa assertiva, se forem comparados os $\beta$ padronizados entre os dois modelos. Note-se que os valores dos coeficientes das variáveis políticas, tanto ideologia quanto estado_mercado, são maiores, ou seja, com maior capacidade explicativa, no modelo 2 , que tem como variável dependente o regionalismo político. 
Um ponto adicional na análise seria pensar que o efeito negativo da variável estado_mercado também pode ser interpretado como válido porque o regionalismo latinoamericano é um projeto fortemente marcado pelos ideais estatizantes de esquerda. Liberais mais convictos, embora sejam poucos na América Latina, seguramente reagem a esse modelo, o que ajuda a dar sentido à interpretação aqui proposta.

Em relação às variáveis de controle, nenhuma delas apresentou significância estatística, o que permite afirmar que as características relacionadas ao mandato, ao background e às características sociodemográficas dos parlamentares não interferem, pelo menos não em termos de significância estatística, na formação de suas preferências em relação ao regionalismo. Diferente do poder explicativo das variáveis de contexto e de preferências políticas e econômicas, que apresentaram significância estatística em ambos os modelos.

Quanto ao ajuste dos modelos, os dois apresentam ajustes bastante satisfatórios. Mas alguns aspectos interessantes saltam aos olhos. O primeiro deles é que as variáveis independentes mobilizadas explicam mais a formação das preferências pelo regionalismo econômico do que pelo político. Note-se que o valor do $\mathrm{R}^{2}$ é maior no modelo cuja variável dependente é o regionalismo econômico $\left(R^{2}=0,280\right)$ que no modelo $2\left(R^{2}=0,227\right)$. Esse dado faz sentido também, visto que temos mais variáveis econômicas (três de contexto e três de pragmatismo econômico) que variáveis políticas nos modelos (apenas ideologia e estado_mercado).

Por outro lado, esse dado também confirma o que já foi assinalado acima. A formação das preferências econômicas realmente é mais afetada por constrangimentos de contexto e pelo pragmatismo do que a formação das preferências por relacionamento político entre países.

\section{Exploração inicial de uma análise complementar}

Como forma de contrastar os resultados até aqui apresentados, foram rodados modelos idênticos tendo como variáveis dependentes as preferências dos parlamentares por relações econômicas e políticas com Estados Unidos e China. A escolha desses países se deve ao fato de eles serem os não latino-americanos apontados pelos parlamentares como de maior interesse (ver análise descritiva).

Os resultados desses modelos não são discutidos de forma pormenorizada aqui, apenas em termos gerais ${ }^{10}$, pois o objetivo principal desse contraste é apenas verificar comparativamente a capacidade explicativa dos modelos aqui apresentados.

A estratégia analítica do contraste se mostrou bastante eficiente e os achados ajudam a sustentar a coerência dos dados e dos modelos aqui sugeridos. Para os modelos com variáveis dependentes de preferências econômicas e políticas por Estados Unidos, as

10 O leitor interessado encontrará os resultados pormenorizados dos modelos no Anexo 1. 
mesmas variáveis apresentaram significância estatística. Os coeficientes, no entanto, tiveram correlação no sentido inverso dos apresentados nos modelos sobre regionalismo econômico e político. De forma resumida, é possível afirmar que os modelos para os Estados Unidos são um negativo fotográfico dos modelos para o regionalismo. Resumidamente, as variáveis de contexto (fazer parte do Mercosul, Alba e Aliança do Pacífico) têm efeitos negativos sobre a formação das preferências dos parlamentares pelos Estados Unidos. Da mesma forma, as variáveis de pragmatismo econômico (abertura comercial, manufatura/PIB e concentração do mercado) também apresentam sentido contrário. Por fim, as variáveis de preferências políticas e econômicas (ideologia e estado_mercado) completam o quadro de contraste, apresentando correlação com sinal invertido se comparadas com os modelos sobre o regionalismo econômico e político.

No caso do contraste com as preferências econômicas e políticas pela China, os resultados são diferentes, mas também ajudam a melhorar a confiança nos modelos de regionalismo aqui apresentados. No que diz respeito às variáveis de contexto (fazer parte do Mercosul, Alba e Aliança do Pacífico), apenas a variável al_pacif apresentou significância estatística. Além disso, o sentido da correlação é positivo. Esse dado é bastante relevante porque mostra que as características da al_pacif são compatíveis com o resultado, visto que esse tratado tem clara orientação para o comércio com países asiáticos. Todas as variáveis do bloco de pragmatismo econômico apresentaram significância estatística para o modelo com a China, mas os sinais das correlações são bastante ambíguos, dificultando a interpretação. Por fim, no plano das preferências políticas e econômicas, a única variável que se mostrou relevante, e ainda assim apenas para o modelo econômico, foi a ideologia. Parlamentares à direita do espectro ideológico rejeitam a China como parceiro econômico, mas a variável estado_mercado nada tem a dizer sobre as preferências dos parlamentares.

Ainda sobre a China, há um último resultado relevante. No modelo sobre preferências quanto às relações econômicas, ainda que de forma ambígua, as variáveis têm algum poder explicativo. Já no modelo sobre preferências políticas, o modelo quase nada tem a dizer sobre as correlações entre as variáveis independentes e dependente.

\section{Comparando os ajustes dos modelos}

Os modelos comparados apresentam diferenças significativas na capacidade de suas variáveis independentes explicarem a variação das dependentes. A Tabela 8 compara a principal medida de ajuste dos modelos, o $R^{2}$ : 
Tabela 8

Comparação da estatística de ajuste dos modelos de regressão

\begin{tabular}{|l|c|c|}
\hline \multicolumn{1}{|c|}{ Modelo } & $\begin{array}{c}\text { Variável dependente } \\
\text { Preferências econômicas }\end{array}$ & $\begin{array}{c}\text { Variável dependente } \\
\text { Preferências políticas }\end{array}$ \\
\hline América Latina (regionalismo) & $\mathrm{R}^{2}=, 280$ & $\mathrm{R}^{2}=, 227$ \\
\hline Estados Unidos & $\mathrm{R}^{2}=, 377$ & $\mathrm{R}^{2}=, 344$ \\
\hline China & $\mathrm{R}^{2}=, 107$ & $\mathrm{R}^{2}=, 021$ \\
\hline
\end{tabular}

Fonte: Elaboração dos autores, com dados do projeto "Elites latino-americanas" (Alcántara, 1994-2018) e dos sites oficiais dos blocos regionais.

Alguns aspectos interessantes saltam aos olhos com essa comparação. O primeiro deles é que as variáveis independentes mobilizadas explicam mais as preferências econômicas que as políticas. Note que os valores do $\mathrm{R}^{2}$ são sempre maiores nos modelos cujas variáveis dependentes são as preferências econômicas. De fato, esse dado faz todo sentido, visto que temos mais variáveis de contexto e de preferências políticas e econômicas que variáveis políticas nos modelos.

Por outro lado, esse dado também confirma o que já foi assinalado acima. A formação das preferências econômicas realmente é mais influenciada por constrangimentos de contexto que as preferências por relacionamento político entre países.

Interessante notar, também, que as variáveis independentes inseridas nos modelos explicam de forma mais convincente as preferências pelos Estados Unidos do que as preferências por regionalismo na América Latina. Esse dado é compatível com o que já havíamos notado na estatística descritiva e na análise de redes. De fato, os Estados Unidos, como maior economia do mundo, desperta o maior interesse econômico.

Por fim, um dado relevante é analisar as medidas de ajuste dos modelos cujas variáveis são as preferências econômicas e políticas pela China. Nesse caso, as capacidades preditivas dos modelos caem substancialmente. Isso autoriza a inferência de que a formação das preferências dos parlamentares pela China é bastante ambígua. Como, aliás, fica claro nos debates mais acirrados sobre o tema. A China hoje é um gigante da economia, que interessa em termos econômicos a qualquer país, claro, mas guarda contradições difíceis de digerir pelos seus pretensos parceiros. Regime político fechado e autoritário, regras de produção que não respeitam a propriedade intelectual, preços de difícil concorrência e relações de trabalho desumanas são apenas alguns fatores que tornam esse parceiro comercial tão desejado quanto perigoso. Não sem razão, as variáveis independentes aqui selecionadas têm pouco a dizer sobre a formação das preferências tanto econômicas quanto políticas dos parlamentares pela China. A China é intrigante para muitos, e para os parlamentares ela não é diferente. 
De forma resumida, o contraste aqui empreendido ajuda a sustentar a relevância das variáveis selecionadas e a coerência dos dados em relação às preferências dos parlamentares por relações comerciais e políticas com seus vizinhos.

\section{Conclusões}

Quando os parlamentares latino-americanos são inquiridos sobre os países com os quais seu país deveria manter relações econômicas e políticas prioritárias, um intrigante puzzle se apresenta. Este artigo resume um esforço analítico para decifrar esse puzzle, buscando encontrar os fatores que podem explicar a formação da complexa estrutura de preferências dos parlamentares da região.

Muito embora os resultados aqui obtidos apontem para preferências extrarregionais em termos de relações políticas e econômicas, especialmente o interesse dos parlamentares pelas grandes potências econômicas como Estados Unidos e China, um grau relevante de regionalismo pode ser identificado nas suas opiniões. Esse regionalismo pode ser explicado por razões tanto de contexto (ou estruturais) como de preferências políticas individuais. Mas um achado relevante é que certamente as razões que explicam as preferências dos parlamentares por relações econômicas regionais são diferentes das razões que explicam a formação de suas preferências por relações políticas.

No que diz respeito à formação das preferências por relações econômicas, o artigo identifica um alto grau de determinação exercido por variáveis estruturais nas opiniões dos parlamentares. Os resultados aqui apresentados sugerem que as opiniões dos parlamentares são fortemente determinadas pelo contexto no qual estão inseridos. As preferências pelo regionalismo econômico estão, em grande medida, determinadas pelo fato de os parlamentares estarem inseridos em países que já fazem parte de algum acordo regional, como a Alba, o Mercosul e a Aliança do Pacífico. A empiria aqui sustentada sugere que, quando um parlamentar é de um país que já faz parte de um acordo regional, a probabilidade de suas preferências serem regionalistas são maiores. A tese aqui sugerida é que a formação das preferências desses parlamentares está informada por um "legado regionalista", que estaria mais presente em parlamentos de países que já têm alguma tradição de cooperação econômica e política regional.

O artigo conclui, ainda, que essas preferências também são fortemente influenciadas por fatores de contexto econômico. O grau de abertura comercial, a dependência da importação de produtos manufaturados e a concentração do mercado exportador do país no qual o parlamentar está inserido informam, em boa medida, por que varia o grau de regionalismo desses parlamentares. Essas variáveis apresentaram poder explicativo sobre a formação das preferências dos parlamentares, mostrando que um relevante grau de pragmatismo econômico orienta suas escolhas. É dizer, quando perguntados sobre os países com os quais seu país deveria manter relações comerciais, os parlamentares respondem 
levando em consideração os constrangimentos e incentivos que afetam as economias de seus países.

Contudo, o artigo sustenta empiricamente que as preferências político-ideológicas dos parlamentares também importam. Parlamentares mais à direita no espectro ideológico tendem a ser menos regionalistas. Da mesma forma, parlamentares que têm preferências por economias mais reguladas pelo mercado do que pelo Estado tendem a ser menos regionalistas, tanto em termos econômicos quanto em termos políticos. Nesse sentido, 0 artigo sustenta que o legado histórico regionalista da esquerda latino-americana continua a moldar as preferências dos seus parlamentares, ao passo que os parlamentares mais liberais continuam a preferir relações com as grandes potências econômicas, especialmente os Estados Unidos.

Quanto os países latino-americanos vão se voltar econômica e politicamente mais para seus vizinhos do que para além-mar não depende, claro, apenas das opiniões das maiorias parlamentares. Na região, as relações comerciais internacionais e a diplomacia política continuam sendo muito mais determinadas pelos chefes do Poder Executivo, que, em contextos presidencialistas, dão o tom das relações exteriores. Mas a relevância dos parlamentos não pode ser subestimada nesses contextos. Para lá se deslocam as elites econômicas e políticas desses países, e negligenciar as opiniões e preferências dessas elites parece pouco prudente.

A questão que se coloca é, portanto, em que medida as opiniões dessas elites políticas continuarão determinadas pelo contexto da dependência econômica e da falta de complementariedade entre as economias da região. Ou, num sentido contrário, em que medida se constituirão em importante suporte dos presidentes para a adoção de políticas internacionais mais compatíveis com suas convicções políticas.

\section{Referências Bibliográficas}

Alcántara, M. (dir.). Proyecto "Elites latinoamericanas" (Pela-Usal). Universidad de Salamanca, 19942018.

ATKINS, G. P. Latin America and the Caribbean in the international system. London: Routledge, 2018.

BOHIGUES, A.; RIVAS, J. "Free trade agreements and regional alliances: support from Latin American legislators". Revista Brasileira de Política Internacional, vol. 62, nº 1, 2019.

BRICEÑo-RUIZ, J. "Ejes y modelos en la etapa actual de la integración económica regional en América Latina". Estudios Internacionales, vol. 45, no 175, p. 9-39, 2013.

BRICeÑo-Ruiz, J.; MoRales, I. Post-hegemonic regionalism in the Americas: toward a Pacific-Atlantic divide? New York: Routledge, 2017.

BRICEÑo-Ruiz, J; SARAIVA, M. "Argentina, Brasil e Venezuela: as diferentes percepções sobre a construção do Mercosul". Revista Brasileira de Política Internacional, vol. 52, no 1, p. 149-166, 2009.

CAICHIOLO, C. R. "The Mercosur experience and theories of regional integration". Contexto Internacional, Rio de Janeiro, vol. 39, nº 1, p. 117-134, 2017. 
Cepal. Comisión Económica para América latina y el CARIBe. El regionalismo abierto en América Latina y el Caribe: la integración económica al servicio de la transformación productiva con equidad. Santiago de Chile: Cepal, 1994.

DABÈNE, O. "Explaining Latin America's fourth wave of regionalism. Regional integration of a third kind". Anais do XXX Congresso Internacional da Latin American Studies Association (LASA), Washington, 23-26 de maio, 2012.

GARDINI, G. L. "Towards modular regionalism: the proliferation of Latin American cooperation". Revista Brasileira de Política Internacional, Brasília, vol. 58, no 1, p. 210-229, 2015.

GARDini, G; LAMBeRT, P. Latin American foreign policies: between ideology and pragmatism. New York: Palgrave Macmillan, 2011.

GrATIUS, S. "The rise of Latin American regionalism: the same old thing?". Madrid: Fundación Ideas (Discussion Papers 01/2012), 2012.

LIMA, M. R. S. "Instituições democráticas e política exterior". Contexto Internacional, Rio de Janeiro, vol. 22 , n० 2, p. 265-303, 2000.

LOPES, D. B.; FARIA, C. A. P.; SANTOS, M. "Foreign policy analysis in Latin American democracies: the case for a research protocol". Revista Brasileira de Política Internacional, Brasília, vol. 59, no 1, 2016.

Malamud, A.; Gardini, G. L. "Has regionalism peaked? The Latin American quagmire and its lessons". The International Spectator: Italian Journal of International Affairs, vol. 47, no 1, p. 116-133, 2012.

Medeiros, M. A.; Teixeira Júnior, A. W. M.; Reis, E. G. "Cooperação para autonomia? Explicando o paradoxo da política externa brasileira para a Unasul". Revista de Sociologia e Política, Curitiba, vol. 25, no 61, p. 97-123, 2017.

NOLTE, D. Regional powers and regional governance. In: GODEHARDT, N.; NABERS, D. Regional powers and regional orders. London: Routledge, p. 49-67, 2011.

QUILICONI, C.; SALGADO, R. "Latin American integration: regionalism à la carte in a multipolar world?". Colombia Internacional, no 92, p. 15-41, 2017.

RiggioRozZI, P. "Region, regionness and regionalism in Latin America: towards a new synthesis". New Political Economy, vol. 17, no 4, 2012.

RiggioRozzi, P.; TUSSIE, D. The rise of post-hegemonic regionalism in Latin America. In: RigGIOROZZI, P.; TUSSIE, D. The rise of post-hegemonic regionalism: the case of Latin America. London: Springer, $\mathrm{p}$. $167-182,2012$.

Salomon, M.; Pinheiro, L. "Análise de política externa e política externa brasileira: trajetória, desafios e possibilidades de um campo de estudos". Revista Brasileira de Política Internacional, vol. 56, no 1, p. 40-59, 2013.

SANAHUJA, J. A. "Del regionalismo abierto al regionalismo post-liberal: crisis y cambio en la integración regional en América Latina". Anais do Anuario de la Integración Regional de América Latina y el Gran Caribe no 7. Managua: Coordinadora Regional de Investigaciones Económicas y Sociales, 2009.

Saraiva, M. G. "As diferentes percepções na Argentina sobre o Mercosul". Contexto Internacional, Rio de Janeiro, vol. 30, no 3, p. 735-775, 2008.

TUSSIE, D. "Relaciones internacionales y economía política internacional: notas para el debate". Relaciones Internacionales, vol. 24, no 48, p. 155-175, 2015. 
VeigA, P. M.; Ríos, S. P. "O regionalismo pós-liberal na América do Sul: origens, iniciativas e dilemas". Cepal Serie Comercio internacional, Santiago, no 82, p. 1-48, 2007.

VigeVANI, T., et al. "O papel da integração regional para o Brasil: universalismo, soberania e percepção das elites". Revista Brasileira de Política Internacional, Brasília, vol. 51, no 1, p. 5-27, 2008.

Vivares, E.; Dolcetti-Marcolini, M. "Two regionalisms, two Latin Americas or beyond Latin America? Contributions from a critical and decolonial IPE". Third World Quarterly, vol. 7, no 13, 2015.

\title{
Anexo I - Variáveis de comércio internacional
}

\begin{abstract}
Abertura comercial
Descrição: A abertura ao comércio é medida como a relação entre comércio e PIB. Mensura a importância combinada de exportações e importações de bens e serviços numa economia, dando uma indicação da dependência tanto dos produtores domésticos em relação à demanda externa quanto dos consumidores domésticos em relação à oferta externa. Existe uma relação côncava entre a abertura comercial e a renda per capita: à medida que a renda aumenta, os países tendem a comercializar mais, mas a uma taxa decrescente.
\end{abstract}

Definição matemática: Onde $X$ é o valor total das exportações, $M$ é o valor total das importações e $Y$ é o PIB do país i no tempo t.

Variação: Um valor de abertura comercial acima de 100 indica que exportações e importações combinadas excedem o PIB; um valor de abertura comercial inferior a 100 implica o inverso.

Limitações: Considerando as demais variáveis constantes, os países maiores tendem a ter relação comercial quanto ao PIB mais baixa, porque podem realizar uma maior parcela de comércio dentro das suas fronteiras. Do mesmo modo, a população e a geografia podem distorcer a abertura comercial; por exemplo, os países sem acesso ao mar tendem a comercializar menos do que países com dimensões e PIB similares, mas com acesso ao mar.

\section{Índice de concentração do mercado Herfindahl-Hirschman}

Descrição: Esse indicador é uma medida da dispersão do valor de comércio entre os parceiros de um país exportador. Um país com uma preponderância do valor comercial concentrado em muito poucos mercados terá um valor do índice próximo de 1 . Assim, é um indicador da dependência do exportador em relação aos seus parceiros comerciais e ao perigo que poderá enfrentar caso os seus parceiros aumentem as barreiras comerciais. Medida ao longo do tempo, uma queda no índice pode ser uma indicação de diversificação nas parcerias comerciais do exportador. Note-se que, se um país exporta apenas para um único mercado, então o indicador não apresenta qualquer valor.

Definição matemática: $X$ é o valor total das exportações do país $\mathrm{i}$, $\mathrm{x}$ é o valor das exportações do país i para o mercado de destino j, e n é o número de mercados parceiros para os quais o país i exporta.

Variação: de 0 a 1 . Um índice mais elevado indica que as exportações estão concentradas em menos mercados, enquanto um país que negocia igualmente com todos os parceiros terá índice próximo de 0 . 
Limitações: Um índice baixo pode não ser um verdadeiro indicador de uma ampla base de parceiros se o número de parceiros for baixo: implica simplesmente que negocia com cada um deles de forma igual.

\section{Parâmetros de escolha:}

Unidade: país

Fluxo comercial: exportações (reportadas ou espelhadas)

Classificação do produto: revisões do HS

Ano: qualquer [até 5]

Produtos: linhas, aglomerados e grupos

Parceiros: países e grupos de países

Anexo II - Modelos para Estados Unidos e China

Regressão preferências econômicas e políticas pelos Estados Unidos

\begin{tabular}{|c|c|c|c|c|c|c|}
\hline \multirow[b]{2}{*}{ Variáveis } & \multicolumn{3}{|c|}{$\begin{array}{c}\text { Modelo } 1 \\
\text { Preferências econômicas EUA } \\
(\mathrm{vd})\end{array}$} & \multicolumn{3}{|c|}{$\begin{array}{l}\text { Modelo } 2 \\
\text { Preferências políticas EUA (vd) }\end{array}$} \\
\hline & $\beta$ & $\beta \_$pad & Pvalor & $\beta$ & $\beta \_$pad & Pvalor \\
\hline (Constant) & ,817 & & ,001 & ,608 & & ,020 \\
\hline \multicolumn{7}{|l|}{ Variáveis de contexto } \\
\hline mercosul & $-1,240$ &,- 406 &, 000 &,- 855 &,- 268 &, 000 \\
\hline al_pacif &,- 519 &,- 175 & ,000 &,- 400 &,- 128 & ,000 \\
\hline alba &,- 467 &,- 160 & ,000 &,- 788 &,- 257 & ,000 \\
\hline \multicolumn{7}{|c|}{ Pragmatismo econômico } \\
\hline abertura_com & ,011 & ,232 & ,002 & ,004 & ,087 & ,264 \\
\hline manufat_PIB &,- 055 &,- 413 &, 000 &,- 029 &,- 208 & ,014 \\
\hline conc_mercado & 1,704 & 181 & ,000 & 1,787 & , 182 & ,000 \\
\hline \multicolumn{7}{|l|}{$\begin{array}{l}\text { Preferências políticas e } \\
\text { econômicas }\end{array}$} \\
\hline ideologia &, 115 &, 220 &, 000 & 129 & ,236 &, 000 \\
\hline estado_mercado & 071 &, 142 &, 000 &, 060 &, 115 &, 000 \\
\hline \multicolumn{7}{|l|}{ Controles } \\
\hline businessman & ,053 & ,017 &, 501 &, 168 & ,051 & ,049 \\
\hline seniority &, 060 & ,036 &, 145 &, 028 &, 016 &, 539 \\
\hline oposição & ,268 &, 104 &, 000 & ,240 & ,089 &, 002 \\
\hline grau_de_instrução & , 138 & ,103 & ,000 & ,088 & ,062 & ,026 \\
\hline estudo_no_exterior &,- 212 &,- 069 & ,009 &,- 060 &,- 019 & ,492 \\
\hline feminino &,- 113 &,- 040 &, 116 &,- 074 &,- 025 & ,342 \\
\hline Estatísticas de ajuste & \multicolumn{3}{|c|}{$\begin{array}{l}\mathrm{N}=1.066 \\
\mathrm{R}^{2}=, 377\end{array}$} & \multicolumn{3}{|c|}{$\begin{array}{l}\mathrm{N}=1.052 \\
\mathrm{R}^{2}=, 344\end{array}$} \\
\hline
\end{tabular}

Fonte: Elaboração dos autores, com dados do projeto "Elites latino-americanas" (Alcántara, 1994-2018) e dos sites oficiais dos blocos regionais. 
Regressão preferências econômicas e políticas pela China

\begin{tabular}{|c|c|c|c|c|c|c|}
\hline \multirow[b]{2}{*}{ Variáveis } & \multicolumn{3}{|c|}{$\begin{array}{c}\text { Modelo } 1 \\
\text { Preferências econômicas China } \\
(v d)\end{array}$} & \multicolumn{3}{|c|}{$\begin{array}{l}\text { Modelo } 2 \\
\text { Preferências políticas China (vd) }\end{array}$} \\
\hline & $\beta$ & $\beta \_$pad & Pvalor & $\beta$ & $\beta \_$pad & Pvalor \\
\hline (Constant) & 1,487 & & ,000 & ,673 & & 000 \\
\hline \multicolumn{7}{|l|}{ Variáveis de contexto } \\
\hline mercosul &,- 155 &,- 061 & 110 &,- 158 &,- 106 & ,009 \\
\hline al_pacif & ,377 & 154 & ,000 &,- 129 &,- 089 & ,038 \\
\hline alba &,- 100 &,- 041 & 262 & $\begin{array}{l}\text { 6,072E- } \\
008\end{array}$ &, 000 & 1,000 \\
\hline \multicolumn{7}{|c|}{ Pragmatismo econômico } \\
\hline abertura_com &, 010 & ,258 &, 004 & ,003 & ,127 & , 186 \\
\hline manufat_PIB &,- 040 &,- 361 & ,000 &,- 014 &,- 211 & ,041 \\
\hline conc_mercado & $-1,226$ &,- 157 & ,000 &,- 028 &,- 006 & ,857 \\
\hline \multicolumn{7}{|l|}{$\begin{array}{l}\text { Preferências políticas e } \\
\text { econômicas }\end{array}$} \\
\hline ideologia &,- 032 &,- 073 &, 049 &,- 004 &,- 017 & ,661 \\
\hline estado_mercado &,- 011 &,- 026 & 468 &,- 009 &,- 037 & 322 \\
\hline \multicolumn{7}{|l|}{ Controles } \\
\hline businessman &,- 040 &,- 015 & 609 &,- 024 &,- 016 & ,620 \\
\hline seniority &,- 037 &,- 026 & ,376 &,- 028 &,- 034 & 283 \\
\hline oposição &,- 188 &,- 088 & ,007 & ,004 & ,003 & 921 \\
\hline grau_de_instrução &, 013 & ,012 & 720 &,- 032 &,- 049 & 149 \\
\hline estudo_no_exterior &,- 035 &,- 014 & 663 &,- 001 &, 000 & ,988 \\
\hline feminino & 011 &, 005 & 880 &,- 075 &,- 053 & ,095 \\
\hline Estatísticas de ajuste & \multicolumn{3}{|c|}{$\begin{array}{l}N=1.066 \\
R^{2}=, 107\end{array}$} & \multicolumn{3}{|c|}{$\begin{array}{l}\mathrm{N}=1.052 \\
\mathrm{R}^{2}=, 021\end{array}$} \\
\hline
\end{tabular}

Fonte: Elaboração dos autores, com dados do projeto "Elites latino-americanas" (Alcántara, 1994-2018) e dos sites oficiais dos blocos regionais.

\begin{abstract}
International economic relations in Latin America: a study on the perceptions of parliamentary elites

This article analyzes the perceptions of parliamentarians from 17 countries in Latin America about economic and international relations. The central issue is to identify the determinants of parliamentarians' preferences. The article seeks to identify which are the determinants that influence the options expressed by parliamentarians, putting in contrast their options for political and economic relations between countries in the region vs. their options for other countries and the main economic powers. The analysis is divided into two parts. The first one is comparative, with descriptive statistics and network analysis. After this analysis, legislatures/countries are compared at the aggregate level. The second part goes down to the level of individual parliamentary behavior, seeking to estimate, with the application of linear regression models (OLS), the weight of different predictors for the formation of their preference structures. The article concludes that parliamentarians' preferences are strongly determined by contextual (structural) variables and a high degree of economic pragmatism, but political ideas continue to have some relevance. Although to a lesser extent, the
\end{abstract}


ideology and preferences for state-regulated economies also help to understand why some parliamentarians defend more political and economic regionalism than others.

Keywords: parliamentary elites; Legislature; Latin America; international economic relations

\section{Resumen}

Relaciones económicas internacionales en América Latina: un estudio sobre las percepciones de las élites parlamentarias

Este artículo analiza las percepciones de parlamentarios de 17 países de América Latina sobre las relaciones económicas e internacionales. El punto central es identificar los determinantes de la formación de estructuras de preferencias parlamentarias. El artículo busca identificar cuáles son los determinantes que inciden en las opciones expresadas por el parlamentario, poniendo en contraste sus opciones para las relaciones políticas y económicas entre países de la región vs. sus opciones para otros países y las grandes potencias económicas. El análisis se divide en dos partes. En la primera se realiza un estudio comparativo en el que se utilizan estadísticas descriptivas y análisis de redes. Con este análisis, las legislaturas/países se comparan a nivel agregado. La segunda parte baja al nivel del comportamiento parlamentario individual, buscando estimar, con la aplicación de modelos de regresión lineal (OLS), el peso de diferentes predictores para la conformación de sus estructuras de preferencia. El artículo concluye que las preferencias de los parlamentarios están fuertemente determinadas por variables contextuales (estructurales) y un alto grado de pragmatismo económico, pero las ideas políticas siguen teniendo cierta relevancia. Aunque en menor medida, la ideología y las preferencias por las economías reguladas por el Estado también ayudan a comprender por qué algunos parlamentarios defienden más el regionalismo político y económico que otros.

Palabras clave: élites parlamentarias; Poder Legislativo; América Latina; relaciones económicas internacionales

\section{Résumé}

Les relations économiques internationales en Amérique latine: une étude sur les perceptions des élites parlementaires

Cet article analyse les perceptions des parlementaires de 17 pays de l'Amérique latine sur les relations économiques et internationales. La question centrale est d'identifier les déterminants de la formation des structures de préférence parlementaire. L'article cherche à identifier quels sont les déterminants qui influencent les options exprimées par le parlementaire, mettant en contraste ses options pour les relations politiques et économiques entre les pays de la région vs. ses options pour d'autres pays et les grandes puissances économiques. L'analyse se divise en deux sections. La première est comparative et elle utilise des statistiques descriptives et une analyse de réseaux. Avec cette analyse, les législatures/pays sont comparés au niveau agrégé. La deuxième section descend au niveau du comportement parlementaire individuel, qui essaye d'estimer, avec l'application de modèles de régression linéaire (OLS), le poids de différents prédicteurs pour la conformation de leurs structures de préférence. L'article conclut que les préférences des parlementaires sont fortement déterminées par des variables contextuelles (structurelles) et par un haut degré de pragmatisme économique, mais les idées politiques continuent à être importantes. Même si dans une moindre mesure, l'idéologie et les préférences pour les économies réglementées par l'État aident également à comprendre pourquoi quelques parlementaires défendent plus le régionalisme politique et économique que d'autres.

Mots-clés: élites parlementaires; Pouvoir législatif; Amérique latine; relations économiques internationales

Artigo submetido à publicação em 25 de setembro de 2018 Artigo ressubmetido à publicação em 27 de julho de 2019. Versão final aprovada em 13 de outubro de 2020.

Opinião Pública adota a licença Creative Commons CC-BY.

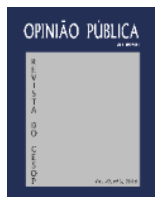

